\title{
APPROACHES TO THE STUDY OF HEREDITARY MUSCULAR DYSTROPHY: RATIONALES AND TECHNIQUES
}

\section{The Fifth National Scientific Workshop}

Sponsored by

The Muscular Dystrophy Association of Canada

November 30 to December 2, 1979

Workshop Coordinators: Dr. Ethel Cosmos - McMaster University Margaret Archibald - MDAC 


\section{1:30 - 9:30 P.M.AFTERNOON SCIENTIFIC SESSION}

\section{The Hamster With Hereditary Muscular Dystrophy}

Session Coordinator: Klaus Wrogemann

The prevention of the hamster hereditary cardiomyopathy by Verapamil, a calcium antagonist Jasmin, G. and Proscheck, L.

$1: 45$

The sequence of necrosis of muscle fibers in the dystrophic hamster

Carpenter, S. and Karpati, G.

Poster \# 1

Approaches used in the investigation of skeletal muscle degeneration in the B10 14.6 cardiomyopathic hamsters: Biochemical, electrophysiological and histological investigations

Elbrink, J.

Poster \#2

Localization of a $\mathrm{Ca}^{\text {t+ }}$-dependent neutral proteinase in hamster lung, heart, and skeletal muscles Elce, J.S., Franchi, L. and Barth, R.

Poster \#3

Protein labelling in dystrophic hamster muscle Nicholls, D.M., Creasy, R.C., Chin-See, M.W. and Saleem, $M$

\section{SESSION I: WHAT IS THE ABNORMAL GENE PRODUCT?}

Session Coordinators: Sergio D.J. Pena and Ronald G. Davidson

Searching for the abnormal gene product(s) in fibroblasts from patients with Duchenne Muscular Dystrophy Wrogemann, $K$.

Cytoskeleton-membrane relationships in normal and dystrophic human fibroblasts

Pena, S.D.J.

Is the abnormal gene product in Duchenne Muscular Dystrophy (DMD) expressed as a defect in the cytoskeleton of fibroblasts in culture? Barber, B. H.

Poster \#4

3:00

A test of allelism in clinical variants of inherited discases

Chang, P.L. and Davidson, R.G.

Changes in the protein synthesis activity of polysomes from fibroblasts of patients and carriers with Duchenne Muscular Dystrophy Brakier-Gingras, L., Boulé, M. and Vanasse, $M$.

Discussion: Posters \#1, 2, 3, 4, 5- MM Level Lobby

\section{CLINICAL SESSION I}

Session Coordinator: Margaret Thompson

$4: 15$

$4: 30$

4:45

Poster \#5
Metabolic differentiation of human skeletal muscle during foetal and postnatal development Elder, G.C. B.

The preclinical stage of Duchenne Dystrophy

Karpati, G., Carpenter, S. and Lemieux, B.

Other tests in relation to serum creatine kinase (CK) measurements for Duchenne Muscular Dystrophy (DMD) carrier detection

Percy, M.E., Andrews, D.F., Chang, L., Lapczak, L., Oss, I., Pichora, G.A. and Thompson, M.W.

Use of antibodies in the detection of mitochondrial creatine kinases

Jacobs, H.K. and Weselake, R.J.
5:00

$5: 15$

$5: 45$ - 6:30 P.M

6:30 - 8:00 P.M.
CK isoenzyme transition in developing skeletal muscle of normal and dystrophic chick embryos Stewart, P.A., Percy, M.E., Chang, L. and Thompson, M.W.

Discussion: Posters \#1, 2, 3, 4, 5 MM Level Lobby Mixer (cash bar) Pavilion C MM Level

Dinner Pavilion C MM Level

Introduction of invited guests:

Melvin L. Moss, Ph.D., Director of Research Development, MDA Alis de Sola, MDA; Michael S. Hudecki, Ph.D., MDA Grantee

\section{8:00 - 9:30 P.M. EVENING SCIENTIFIC SESSION}

\section{CLINICAL SESSION II}

Session Coordinator: Alan J. McComas

$8: 00$

Passive transfer of demyelinating activity in experimental allergic neuritis and Guillain-Barré polyneuropathy

Hahn, A.F., Feasby, T.E. and Gilbert, J.J.

Poster \#6 Passive transfer of demyelinating activity in experimental allergic neuritis

Hahn, A.F., Feasby, T.E. and Gilbert, J.J.

$8: 15$

$8: 20$

\section{Discussion}

Orthopaedic aspects of Duchenne Muscular Dystrophy (Medical engineering and computer analysis) Moseley, C.F. and Koreska, J.

9:10

Discussion: Posters \#1, 2, 3, 4, 5, 6 MM Level Lobby

\section{SATURDAY, DECEMBER 1}

9:00 A.M. -

1:00 P.M.

MORNING SCIENTIFIC SESSION

SESSION II: WHEN DURING DEVELOPMENT IS THE ABNORMALTY EXPRESSED?

Session Coordinators: Paul C. Holland and David H. MacLennan 9:00

The embryonic origin of avian brachial muscles Beresford, B.

9:15

The avian latissimus dorsi: I. Role of neurons to establish embryonic enzymic patterns Butler, J, and Cosmos, E.

Poster \#7 II. Physiological and structural comparisons of the phenotypically affected PLD and the spared ALD Mazliah, J. and Cosmos, E.

Neural extracts do not influence acetylcholinesterase activity in muscle cultured from dystrophic chick embryos

Johnson, D.D., Bailey, S. and Wenger, B.

9:45

Biosynthesis of plasma membrane proteins in normal and dystrophic muscle Holland, P.C. and Cates, G.A.

$10: 00$ Localization and biosynthesis of the high affinity calcium binding protein of sarcoplasmic reticulum Michalak, M. and MacLennan, D.H.

$10: 15$

11:00 Discussion: Posters $\# 7,8,9,10 \mathrm{MM}$ Level Lobby The quantitation of free and IRNA bound amino acids obtained from single monolayer cultures of skeletal muscle

Bullaro, J.C. 
11:15 Patterns of muscle protein metabolism in dystrophic chick and mouse embryos

Monckton, G. and Nihei, T.

11:30 Myofibril isolation for protein turnover studies in cultured skeletal muscle

Janeczko, R.A.

11:45 Electrophysiological development in dystrophic muscle

Dryden, W.F. and Thomson, C.M.

12:00 Control of muscle cell growth and amino acid transport

Logan, W.J.

Fate of low molecular weight glycoproteins in myoblast cytodifferentiation

NG, S.K.

Poster \#8 Selection and fusion properties of concanavalin A resistant myoblast cell lines

Parfett, C.L.J., Wright, J.A. and Jamieson, J.C.

Poster \#9 A method for the rapid isolation of mitochondria from skeletal and cardiac muscles suitable for small tissue samples

Goswami, T., Parvin, R. and Pande, S.V.

12:30 Discussion: Posters $\# 7,8,9,10 \mathrm{MM}$ Level Lobby

1:00 - 2:00 P.M. Lunch Pavilion C MM Level

Lunch

$4: 30$

$4: 45$

5:00

$5: 15$

$5: 45-6: 30$

$6: 30-7: 45$
Measurement of intracellular ionic activity in normal and dystrophic mouse muscle using ion selective microelectrodes Silverman, H., Charton, M.P. and Atwood, H.L.

A quantitative immunochemical and polyacrylamidegel fluorographic analysis of protein synthesis in dystrophic murine skeletal muscle

Atkinson, B.G. and Shivers, R.R.

Studies of a protein synthesis inhibitor in dystrophic mouse muscle

Chin-See M.W. and Nicholls, D.M.

Discussion: Posters \#7, 8, 9, $10 \mathrm{MM}$ Level Lobby

Mixer (cash bar) Pavilion C MM Level

Dinner Pavilion C MM Level

\section{8:00 - 9:30 P.M. EVENING SCIENTIFIC SESSION SESSION III(Part II): WHERE IS THE ABNORMAL- ITY EXPRESSED?}

Session Coordinators: Peter Vaughan and Richard Stein

Intramembrane architecture of dystrophic murine skeletal muscle sarcolemna; a freeze-fracture study Shivers, R.R. and Atkinson, B.G.

$8: 15$ Measurements of membrane fluidity in dystrophic mice Mizobe, F., Martial, E. and Livett, B.G.

2:00 - 5:30 P.M. AFTERNOON SCIENTIFIC SESSION CLINICAL SESSION III

Biochemical and immunochemical studies of peripheral blood lymphocytes (PBL) in Duchenne Muscular Dystrophy (DMD)

Session Coordinator: Colin F. Moseley

2:00

$2: 20$

Poster $\# 10$

$2: 40$

3:00

Trial of penicillamine in the management of the Duchenne type of dystrophy

Murphy, E.G.

Penicillamine induced myasthenia gravis

Lang, A.E. and Humphrey, J.G.

Trials of oral phenytoin in dystrophic chickens; effect on contractile and electrical properties

Hoekman, T.

Plasma exchange and myasthenia gravis

Humphrey, J.G., Lang, A.E., Shumak, K.H. and McLean, D.R.

Discussion: Posters \#7, 8, 9, 10 MM Level Lobby

\section{SESSION III(Part I): WHERE IS THE ABNORMAL- ITY EXPRESSED?}

Session Coordinators: Joseph J. Gilbert and Alan C. Peterson

$3: 30$

$3: 45$

4:00

$4: 15$
Microscopic evaluation of soleus and extensor digitorum longus (EDL) muscles in young dystrophic mice of the C57BL/6J dy $2 \mathrm{~J} /$ dy $2 \mathrm{~J}$ strain Ovalle, W.K. and Shinn, S.L.

Isometric contractile properties of dystrophic mouse muscle of the $\mathrm{C} 57 \mathrm{BL} / 6 \mathrm{~J}$ dy $2 \mathrm{~J} / \mathrm{dy} 2 \mathrm{~J}$ strain Bressler, B. H.

Study of the distribution of proteins in slow-twitch and fast-twitch muscles of normal and dystrophic mice

Jasch, L.G.

Motorneuronal involvement and fibre type susceptibility in dy2J mice

Parry, D.J.
Percy, M.E., Trew-Marshall, B.J., Chang, L., Freedman, M.H. and Thompson, M.W.

$8: 45$

The current status of erythrocyte membrane abnormalities in muscular dystrophies - A review Rathbone, M.P.

9:00

Discussion: Posters \#1 - 10 MM Level Lobby

\section{SUNDAY, DECEMBER 2}

9:00 A.M. -

12:15 P.M.

MORNING SCIENTIFIC SESSION

SESSION III(Part III): WHERE IS THE ABNORMALITY EXPRESSED?

Session Coordinators: George Karpati and Bruce G. Livett

9:00

$9: 15$

9:30

9:45

Myelination in the peripheral nerve of normal and muscular dystrophic chicks during development Mezei, C. Highly localized alterations in endogenous phos-
phorylation of myelin proteins in murine dystrophy Petrali, E.H. and Sulakhe, P.V.

Schwann cell abnormalities in dystrophic mice Perkins, C.S., Bray, G.M. and Aguayo, A.J.

Gene product distribution in mosaic skeletal muscle fibres

Frair, P., Peterson, A.C.

10:00

Dystrophic-normal mouse chimaeras: Extramuscular influences in the expression of the muscle disease

Peterson, A.C., Frair, P., Rayburn, H. and Cross, D.
Discussion: Poster \#11 MM Level Lobby 
Poster \#11 An hypothesis: A primary thymic defect contributes to an abnormal immune response and muscle disorder in murine muscular dystrophy

Szewczuk, M.R.

$10: 45$

11:00

$11: 15$
An assessment of thymic factors in the expression of muscular dystrophy in mice

Slonecker, C.E.

Thymic mast cells in the genesis of avian muscular dystrophy

Befus, A.D., Johnston, N., Bienenstock, J., Butler, J. and Cosmos, E.

Investigation of possible immunocyte involvement in the murine muscular dystrophies

Colby-Germinario, S., Martial, N. and Livett, B.G.
11:30

$11: 45$

12:15 - 1:15 P.M.

Prostaglandin regulation of porphyrin biosynthesis: Abnormality of protoporphyrin in Bar Harbor 129 mice

Morgan, R.O. and Horrobin, D.F.

Discussion: Poster \#1 MM Level Lobby

Lunch

Pavilion C

MM Level

\section{1:15 - 3:15 P.M. OPEN FORUM}

\section{GROWING TIPS AND FUTURE TRENDS}

Session Coordinator: Jack Diamond 


\author{
Prevention of the Hamster Hereditary Cardiomyopathy \\ by Verapamil, a Calcium Antagonist \\ G. Jasmin and L. Proschek, Département de pathologie, \\ Université de Montréal
}

Since we demonstrated 6 years ago the prevention by Verapamil of the hamster cardiomyopathy, the question arises regarding the prominent role of calcium in the genesis and progression of this hereditary disease. We tested a number of similarly acting drugs including adrenergic blockers. Most preparations were found to be active against heart necrosis, but less effective in preventing skeletal muscle lesions. One possible explanation is that myocardial cell contractility, contrary to that of skeletal muscle, is dependent on the inflow of extracellular calcium as are smooth muscle cells. It was postulated that some abnormality existed in the plasma membrane either in structure or function with resulting abnormal movements of $\mathrm{Ca}$ into the slow channels. Catecholamines can also increase the calcium inflow into heart muscle cells and the phenomenon is readily prevented by $\mathrm{Ca}$ antagonists. Another pertinent question deals with the influence of mitochondrial calcium overload on muscle cell energy pool. We knew that short term treatment with Verapamil improved the mitochondrial respiratory activity in cardiomyopathic hamsters, but only recently we were able to extend the treatment for one year by using the methoxy derivative known as Cpd D-600. While entirely preventing the heart necrotic changes with resulting prolongation of the life span of the diseased animals, it became evident that the calcium antagonist cannot interfere with the underlying plasma membrane defect responsible for this hereditary disease. Long treated animals still exhibited heart hypertrophy with myolytic changes; the cardiac insufficiency, however, did not invariably lead to manifestation of congestive heart failure. The progression of the polymyopathy was unchanged in these long treated animals.

\section{The Effect of 2,4-Dinitrophenol on the Electrical Activity of Normal and Dystrophic Diaphragm.}

E.G. Hunter and J. Elbrink, Edmonton, Alberta.

A number of differences between BIO 14.6 hamsters (dystrophic) and random bred controls (normal) have been described, including a defect in mitochondrial energy generation. The contribution of anaerobic and/or aerobic metabolism to the maintenance of the resting membrane potential in skeletal muscle has not yet been firmly established. Therefore, the effect of 2,4-dinitrophenol (DNP) on the electrical activity of diaphragm from 5764 day old random bred and BIO 14.6 hamsters has been investigated.

The muscles were superfused with Krebs-Henseleit bicarbonate buffer containing $1.27 \mathrm{mM} \mathrm{Ca}^{2}+$ and $5 \mathrm{mM}$ D-glucose at $30^{\circ} \mathrm{C}(\mathrm{pH} 7.4)$. Resting membrane potentials (RP's) were obtained from surface fibers with microelectrodes filled with $3 \mathrm{M} \mathrm{KCl}$. Action potentials (AP's) were displayed on an oscilloscope and photographed.

The RP's of dystrophic diaphragm were slightly but significantly lower than those of the normal muscle. The AP's of muscle from BIO 14.6 hamsters were similar in magnitude than those of the controls but increased with time to values greater than those in normal muscle. DNP $(0.15 \mathrm{mM})$ decreased the RP's and AP's with the same time course in both groups of tissues; the RP's were significantly decreased after 15 min, the AP's after 30 min. In dystrophic muscle fewer AP's could be obtained in the presence of the uncoupler.

Thus, only minor differences exist in the electrical activity of dystrophic and normal diaphragm.

\section{$\mathrm{CA}^{++}$Dependent Neutral Proteinase in Hamster Lung, Heart, and Skeletal Muscle}

John S. Elce, R. Barth and L. Franchi, Kingston, Ontario

It has been suggested that a membrane defect in some forms of muscular dystrophy leads to local disturbances in intracellular calcium levels, which may cause an increase in activity of the calcium-dependent neutral proteinase and an increased rate of loss of muscle cell protein. The proteinase is present in extracts of most tissues, but has the highest specific activities in lung and in platelets. This hypothesis of muscle breakdown requires that the calcium-dependent proteinase actually be located within the muscle cell, rather than in other cell types, and we are investigating this localization with immunocytochemical techniques.

The calcium-dependent proteinase was extracted from hamster skeletal muscle by homogenization and centrifugation, and purified by gel filtration, ion exchange, and affinity column chromatography. The final product was at least $90 \%$ pure (SDS-gel electrophoresis) and was used to raise antisera in two rabbits. The antibodies were monospecific as judged by rocket immunoelectrophoresis. They are being used both for immunofluorescence studies with frozen, unfixed tissue sections of normal hamster, and for immunoperoxidase studies with fixed tissues.

The preliminary immunoperoxidase studies suggest in the lung a localization in polymorphonuclear leukocytes. In muscle they suggest a localization in the muscle cell membranes and in granular cells which may be mast cells.

Protein Labelling in Dystrophic Hamster Muscle

Nicholls, D.M., Creasy, R.C., Chin-See, M.W. and Saleem, M., Toronto, Ontario

The incorporation of amino acids was measured in protein fractions of muscle in intact control and dystrophic female hamsters and also in cell-free preparations obtained from these animals. The labelling of the soluble sarcoplasmic protein fraction, the microsomal protein fraction, and the sarcolemna protein fraction was increased markedly in the dystrophic hindleg muscle. The relative specific activities of the microsomal and sarcoplasmic protein fractions were increased and, together with the results from the cell-free preparation, suggest that protein synthesis is increased in the dystrophic leg muscle.

\section{Searching for the Abnormal Gene Product(s) in Fibroblasts} from Patients with Duchenne Muscular Dystrophy

K. Wrogemann, R.G. Thompson, E. Rosenmann and S.D.J. Pena, Winnipeg, and Montreal

Our approach is based on the two assumptions that the abnormal gene product in Duchenne muscular dystrophy (DMD) is a protein and that it is expressed in fibroblasts. With that caveat in mind we studied the incorporation of protein precursors into individual proteins using extensive protein fractionation by one - and two dimensional gel-electrophoresis technique in combination with double labeling. The latter allowed for exact reproducibility of the separation method between normal and dystrophic cell strains.

Three major problems had to be overcome: (i) the number of potential gene products is enormous (some 50,000 or so). (ii) the problem of biochemical individuality (i.e. the normal, genetically determined variations in each individual's proteins may be difficult to distinguish from the protein alteration(s) that cause(s) Duchenne dystrophy). (iii) the problem of genetic heterogeneity (i.e. the probability that at the molecular level DMD represents more than one disease entity.

As DMD is an X-linked disease we attempted to isolate $\mathrm{X}$-directed proteins with antisera from rodents immunized with human-rodent hybrid cells carrying only the $X$ from the human genome. By pooling fibroblasts from many persons or by studying cloned cells from carriers we tried to overcome the problem of polymorphism, while the problem of genetic heterogeneity was avoided by studying many members from large families with DMD. The approach lends itself to continuous refinements.

\section{Cytoskeleton-Membrane Relationships in Normal and Dystrophic Human Fibroblasts Sergio D.J. Pena}

Department of Neurology and Neurosurgery, McGill University and Biochemical Genetics Laboratory, Montreal Neurological Institute Montreal, Quebec

It has been reported that ligand-induced cap formation of surface receptors is abnormal in lymphocytes from patients with Duchenne Muscular Dystrophy (DMD). Although this observation could not be reproduced in other laboratories, it led me to examine the cytoskeletonmembrane relationships of cultured skin fibroblasts from normal and DMD patients. 
Although rigid quantitative criteria were not employed, no differences were found in the ability of control and dystrophic fibroblasts to cap surface concanavalin A receptors. Moreover, no differences were found on morphological organization of the cystoskeleton from normal and DMD fibroblasts as estimated by immunoperoxidase visualization with specific anti-actin, anti-tubulin and anti-myosin antisera as well as with a newly developed coomassie blue staining technique. Fibronectin (LETS), a surface fibroblast component associated with the cytoskeleton, also had identical organization in control and DMD cells.

\section{Is the Abnormal Gene Product in Duchenne Muscular Dystrophy (DMD)} Expressed as a Defect in the Cytoskeleton of Fibroblasts in Culture? by B.H. Barber, Toronto

We have addressed ourselves to the question of whether or not the expression of the DMD genotype influences the organization or function of cytoskeletal components in non-muscle cells such as fibroblasts. By the cytoskeleton, we refer to those proteins comprising or associated with the complex network of intracellular filamentous structures which span the cytoplasm and include microfilaments, microtubules and the system of intermediate (i.e. $100 \mathrm{~A}^{\circ}$ ) filaments. As the experimental system, we have used fibroblasts established in culture from skin biopsies of persons with DMD or from age and sex-matched control individuals. The initial objective has been to examine comparatively, by means of immunofluorescence, the intracellular distribution of cytoskeletal components in the control and DMD fibroblasts. Complimentary one- and two-dimensional electrophoretic techniques have also been employed to permit a more detailed and quantitative approach to the comparison of the cytoskeleton in each cell type. To date we have applied this type of analysis to a study of actin, the major contractile component in non-muscle cells, and more recently tubulin, the monomeric subunit of microtubules. The results of these comparisons in each case suggest that there are no obvious differences in the structural organization of these components when comparing the DMD fibroblasts with those from control individuals.

\section{A Test of Allelism in Clinical Variants of Inherited Diseases}

Patricia L. Chang and Ronald G. Davidson

Department of Pediatrics, McMaster University, Hamilton, Ontario

In hereditary muscular dystrophy, as in many other hereditary diseases, common pathological features or biochemical defects are often associated with variable clinical presentations. The genetic relationship among these clinical variants may be elucidated in some cases by our newly developed technique of non-selective isolation of human euploid hybrid cells.

Rationale: Suppose there are two clinical variants of what is apparently, the same hereditary disease, each associated with deficiency of a measurable entity, Y. If they are due to defects at different genetic loci (non-allelic), hybrid cells formed between them should have at least one correct copy of all the genes. Therefore, in these hybrids, entity Y should be restored. In contrast, if the defects are at the same genetic locus (allelic), normal $Y$ would not be restored.

Technique: Cultured cells from the two variants are treated with a fusing agent. Cells from the resulting mixture of unfused parent cells and fused cells are separated according to size by gravity sedimentation. A population enriched in double-nucleated cells is obtained and cloned. The hybrid nature of the clones can be established by showing double the diploid number of chromosomes along with presence of markers of both parent cell strains; e.g. antigenic or isozymic characteristics. The entity $\mathrm{Y}$ is measured in these hybrids to determine whether intergenic complementation has occurred or not.

This approach has been used successfully to show that in an inherited neurodegenerative disease, metachromatic leukodystrophy (MLD), the infantile and adult-onset variants are due to allelic mutations whereas the usual form of MLD (characterized by deficient arylsulfatase $A$ activity) and an $\mathrm{O}$-variant (characterized by deficient arylsulfatase $\mathrm{A}, \mathrm{B}$ and $\mathrm{C}$ activities) are probably due to non-allelic mutations.
Changes in the Protein Synthesis Activity of Polysomes from Fibroblasts of Patients and Carriers with Duchenne Muscular Dystrophy

Léa Brakier-Gingras, Marie Boulé et Michel Vanasse

Département de Biochimie, Université de Montréal

et Section de Neurologie, Hôpital Ste-Justine, Montréal

Polysomes (ribosomes bound to endogenous Messenger RNAs) from cultured fibroblasts of patients and carriers with Duchenne Muscular Dystrophy (DMD) were isolated by differential centrifugation following standard procedures. Their distribution was analyzed by centrifugation through a $20-50 \% \mathrm{w} / \mathrm{v}$ linear sucrose gradient and their activity was measured by determining the amount of $(14 \mathrm{C})$ leucine incorporated into trichloroacetic acid insoluble material, using an in vitro system where the $105,000 \mathrm{~g}$ supernatant of wheat germ lysate was the source of soluble enzymes and rRNAs. No significant difference could be observed in the sedimentation profile of polysomes but protein synthesis assays with polysomes from $10 \mathrm{DMD}$ carriers and $10 \mathrm{DMD}$ patients revealed that their activity was lower than the activity of normal controls (1.5-fold and 3-fold respectively). However, when endogenous messenger RNAs were digested with micrococcal nuclease and protein synthesis directed with an exogenous synthetic messenger (poly (U)), no significant difference could be detected in the activity of ribosomes from DMD carriers and patients and from normal controls. Analysis of poly (U)-dependent protein synthesis can be used for the detection of changes in the activity of ribosomes in the elongation step of protein synthesis, as the normal process of initiation is bypassed. Therefore, our data suggest that the difference in the activity of polysomes from DMD carriers and patients, observed when using natural endogenous messengers, result from a defect affecting the initiation step of protein synthesis.

\section{The Preclinical Stage of Duchenne Dystrophy \\ George Karpati, Stirling Carpenter and Bernard Lemieux Montreal}

The time when characteristic morphologic abnormalities may first be detected in Duchenne muscles is uncertain. In this study of 2 patients, we provide evidence that destruction of muscle cells is extremely active in early postnatal life in Duchenne dystrophy. However, until muscle fiber loss (due to failure of adequate regeneration) reaches a critical degree, overt clinical weakness is not evident.

Two cousins were found to have 36 and 75 fold increase of serum creatine kinase (CK) activity in the neonatal period as a result of a routine screening program. The serum CK activity of one of the patient's mother was also increased $5 \mathrm{x}$ above normal confirming her carrier state. The motor development of the children at least until the time of their muscle biopsy at 10 and 18 months of age respectively was normal, but their serum CK activity further increased to 250 - $400 x$ above normal. Examination then was unremarkable except mild enlargement of the calves. Biopsy of biceps brachii of both patients revealed numerous groups of muscle fibers undergoing segmental necrosis or regeneration. Hypercontracted fibers were common, connective tissue excess was present. By electronmicroscopy, gaps of the plasma membrane were seen in non-necrotic muscle fibers which had dilated membrane bound spaces. Focal breakdown of plasma membrane leads to necrosis unless it is repaired. In support of this suggestion, we found muscle fibers in which single or multiple layers of basal lamina were separated from a dimpled surface of the cell. Empty basement membrane sheaths indicating failure of regeneration were present.

\section{A Combination of Four Serum Tests for Duchenne Muscular Dystrophy Carrier Detection \\ M.W. Thompson, D.F. Andrews, L.S. Chang, L. Lapczak,} I. Oss and M.E. Percy

Department of Genetics, Hospital for Sick Children and Department of Statistics, University of Toronto, Toronto, Canada

Measurement of serum creatine kinase (CK) activity is the most commonly applied test for carrier detection in Duchenne muscular dystrophy (DMD). In our laboratory in a single test, only $55 \%$ of adult carriers have an elevated CK level. However, by using an average of three independent $\mathrm{CK}$ measurements per individual to define the distribution of 
CK activities in controls and females at risk, the detection rate of DMD carriers aged 20 to 40 years can be increased to 75 or $80 \%$.

We have confirmed preliminary reports from other laboratories that serum pyruvate kinase activity, lactate dehydrogenase activity and hemopexin concentration reflect the DMD carrier state. In a study of single serum samples from 20 genetically defined DMD carriers and 50 female controls (all between the ages of 20 and 40 years), 18 of the 20 carriers including 5 of 7 with serum CK levels in the normal range could be distinguished from $95 \%$ of the controls using simple two- and threedimensional plots of results from these three tests in combination with $\mathrm{CK}$ data.

Ultimately, multivariate analysis will be used (i) to combine these data (ii) to ensure that the percentage of "false-positive" results do not exceed an acceptable level, since in any one test these may be as high as $5 \%$ and (iii) to determine which combination of these tests and others being assessed in our laboratory are most effective in discriminating between normals and carriers.

Our current data suggest that this approach will greatly improve DMD carrier detection as it has in a variety of other genetic disorders.

\section{Use of Antibodies in the Detection of Mitochondrial Creatine Kinases}

Hans $K$. Jacobs and Randall J. Weselake, Winnipeg

The assay of serum creatine kinase (CK) aids in the early diagnosis of Duchenne MD and is useful in distinguishing it from other forms of MD and other muscle diseases. The appearance in serum reflects loss of enzyme from damaged muscle cells. Lowering of serum enzyme levels in later stages of the disease indicates decreased muscle mass and insufficiency of repair processes. Isoenzyme studies on muscle from Duchenne MD cases have shown the occurrence of the muscle specific $M M$ cytoplasmic form as well as the presence of $\mathrm{MB}$ and $\mathrm{BB}$ isoenzymes of CK. This reversal to or retention of a fetal type $C K$ isoenzyme pattern in muscle is reflected in serum where the MB isoenzyme can be detected frequently. Participation of the mitochondrial isoenzyme of creatine kinase $(\mathrm{m}-\mathrm{CK})$ in the development of MD has been suggested recently. Loss of this isoenzyme which is the CK form to arise in muscle only shortly before birth, would indicate that reversal to a fetal pattern and not retention of an early pattern is typical of Duchenne MD. Mitochondrial CK so far has not been discovered in serum. This appears to be due to the great instability of the mitochondrial isoenzyme, leading to inactivation as soon as it enters the serum. We have isolated in pure form mitochondrial creatine kinases from bovine and human heart and from bovine and human brain. These enzymes were used to raise antibodies. Cytoplasmic and mitochondrial forms of CK can be clearly distinguished using these antibodies. Mitochondrial creatine kinases from heart and brain are immunologically distinct. It should therefore be possible to determine the occurrence of $\mathrm{m}-\mathrm{CK}$ in serum from MD patients with immunological methods.

\section{CK Isozyme Transition in Developing Skeletal Muscle of Normal and Dystrophic Chick Embryos}

P.A. Stewart, M.E. Percy, L. Chang, and M.W. Thompson

Department of Anatomy, University of Toronto, Toronto, Ontario and the Department of Medical Genetics, Hospital for Sick Children, Toronto, Ontario

Three main forms of creatine kinase (CK) have been identified: the homodimeric isozymes $\mathrm{MM}$ and $\mathrm{BB}$, and the heterodimeric isozyme $\mathrm{MB}$. The subunits are probably coded by separate loci, $\mathrm{CK}_{\mathrm{M}}$ and $\mathrm{CK}_{\mathrm{B}}$ respectively. $\mathrm{CK}_{B}$ is the principal locus expressed in most adult and embryonic tissues. In developing skeletal muscle the $\mathrm{CK}_{M}$ locus becomes progressively more active. The isozyme transition from predominately BB to predominately $M M$ is a useful index of muscle differentiation.

In most human neuromuscular diseases, the total CK activity is decreased in the muscle tissue and increased in the serum. In addition, significant amounts of $\mathrm{MB}$ and $\mathrm{BB}$ isozymes have been identified in muscle and sera from patients with $\mathrm{X}$-linked muscular dystrophy. It is not clear, however, whether this "fetal" pattern of isozymes is due to the presence of regenerating fibers, or whether $\mathrm{CK}$ isozyme transition is incomplete in dystrophic muscle.
Since these features are also common to chicken muscular dystrophy, CK isozyme transition was studied in tissues of normal and dystrophic chick embryos. We found that the activity of the $M$ subunit was significantly lower in both pectoral and thigh muscles of the dystrophic embryos. In addition, at one week ex ovo, total CK activity per $\mathrm{mg}$ wet weight of tissue was significantly lower in brain as well as in the pectoral and thigh muscles of the dystrophic birds. Thus expression.and/or activities of the products of both the $\mathrm{CK}_{\mathrm{M}}$ and $\mathrm{CK}_{\mathrm{B}}$ loci appear to be affected in chicken dystrophy.

\section{Passive Transfer of Demyelinating Activity in Experimental Allergic Neuritis and Guillain-Barre Polyneuropathy \\ A.F. Hahn, T.E. Feasby, J.J. Gilbert, London, Ontario}

To clarify the disputed role of humoural factors in the immunopathogenesis of experimental allergic neuritis (EAN), and Guillain-Barre polyneuropathy, we have studied the demyelinating activity of EAN serum and serum from patients with acute GBP in vivo, using the technique of direct intraneural injection.

EAN rabbit sera were injected into sciatic nerves of Wistar rats. Focal segmental demyelination developed rapidly at the site of injection. Alteration of Schwann cell cytoplasm and myelin degradation with preservation of axons evolved within hours, prior to the appearance of inflammatory cells. Sequential studies showed macrophage invasion and phagocytosis of myelin debris. The demyelination was maximal at four days, involving up to $75 \%$ of the fascicular area. Progressive remyelination was seen beginning by day eight. Control injections into the contralateral sciatic nerve were negative. The demyelinating factor(s) was shown to be tissue specific by absorption studies. Direct immunofluorescence demonstrated IgG bound to myelinated fibres.

Serum from 7 patients with acute Guillain-Barre polyneuropathy was similarly injected. In 6 of these, scattered foci of demyelination were present, predominantly around the endoneural veins. This was associated with perivenular lymphocytes and macrophages.

These in vivo studies strongly suggest that circulating antibodies participate in the demyelination of both EAN and Guillain-Barre polyneuropathy. However, the pattern of demyelination differed in the two conditions. In addition, participation of lymphocytes in the inflammatory response was present only after GBP serum injection.

\section{Orthopaedic Aspects of Duchenne Muscular Dystrophy (Medical Engineering and Computer Analysis) C.F. Moseley and J. Koreska Toronto}

Progressive muscular weakness is a primary cause for the development of spinal deformities (scoliosis) in children with Duchenne Muscular Dystrophy.

The onset of the deformation process usually coincides with the period when the child is no longer able to ambulate and becomes completely confined to a wheelchair. Unless checked, these deformities progress relentlessly and in the course of a few years the child is no longer able to sit in his wheelchair. Although the development of spinal deformities is predictable the underlying structural biomechanics of the deforming spine is extremely complex. Also, the characteristics of the material which constitute the load-bearing components of the spine, are to a large extent unknown. Therefore, effective orthopaedic management of spinal deformities in DMD is difficult without a thorough understanding of the underlying structural processes occurring during the development of these deformities.

Conventional orthopaedic assessment of spinal deformities is based on 2dimensional projections ( $x$-ray films) of spinal deformities which actually occur in 3-dimensional space.

To gain a better understanding of the 3-D geometry of the deforming spine in non-ambulatory DMD children we have developed an approach using conventional spine $x$-ray films and a computer/digitizer system which gives an exact analysis and 3-dimensional representation of the spine geometry. This approach allows the orthopaedic consultant to identify and assess the real deformity and to deal more effectively with the problem of the unstable deforming spine. In some cases, it is possible to predict the onset of instability and prophylactic treatment can be implemented before 
the deformity becomes a problem

The computer analysis includes the calculation of conventional orthopaedic parameters such as Cobb angles, pelvic obliquity, sacral angle, etc. However, much more detailed data is generated on the complete 3dimensional geometry of the spine such as the 3-D "Cobb" angle, curve limits, curve apices, length of spine segments (for monitoring of growth spurts), apical views of the spine and projected areas.

At the present time the system is able to provide the following:

1. Digitizing of current spine radiographs in a few minutes while the patient is present.

2. A complete 3-D analysis of the spine geometry in a few seconds.

3. Numerical and graphical presentation of results with hard copy for inclusion in the patient's file.

4. Store the digital data from the radiographs and the results of the analysis for later review.

5. Reviews of previous examinations and a summary report on examinations selected for review in both numerical and graphical form.

6. Review the entire data file containing results of the latest analyses for each patient or review any subgroup of patients selected from the file according to specified criteria. The review includes:

a) Listing of the results

b) Sorting data by numerical or alphabetical order

c) A summary statistical analysis on any numerical variables stored in the file

d) Polynomial regression analysis with scatter plot for any two variables

7. Several options for graphical presentations including:

a) Rotation of the P-A view into the plane of maximum spine curvature

b) A perspective view from any angle of rotation and tilt

Embryonic Development of Avian Brachial Muscles

Bonnie Beresford, Pathology Department, McMaster University Health Sciences Centre, Hamilton

One approach to the analysis of developmental events of muscles of dystrophic genotype is to culture fetal muscles in vitro in an attempt to control extramyogenic factors important to differentiating events. However, a second approach is to permit the natural embryonic environment to serve as the culture medium and to design experiments in ovo rather than in vitro. To use this approach, we must first define the embryonic origin and the eventual fate of muscles of specific interest.

Studies with the avian dystrophic model have identified the fast twitch glycolytic fibers as targets for disease expression and most specifically the pectoralis major muscle. My present experiments were designed to map the origin and development of the pectoralis major muscle (and other wing associated muscles) of the normal chicken (White Leghorn) using interspecific chimaeras between quail and chick embryos. The technique of inter-specific chimaeras takes advantage of the difference in the characteristic staining and distribution of chromatin between quail and chick nuclei as noted with the Feulgen technique, a stain specific for DNA. With this marker, the fate of transplanted tissue can be followed and the origin of specific muscles can be mapped accurately. Thus somites, lateral mesoderm and limb buds of quail embryos are transplanted orthotopically to chick embryos from which the corresponding tissues have been removed. Donor and host embryos are at the same stage of development. Following appropriate incubation periods, the chimaeras thus formed are prepared for paraffin sections, stained for nuclear DNA and analyzed.

Mapping results with the quail-chick chimaera reveal that all wing and wing-associated muscles of the chick, including the pectoral and latissimus dorsi musculature, arise from the dorsal wall of somites $16-21$ as seen in stage 14 embryos ( 2 days). Furthermore, between stages 14 and 18 (2-2.5 days) the migration of these myogenic precursor cells into the developing limb bud is complete, e.g., all myogenic precursors of the pectoralis major are now located in the limb bud and will eventually migrate from this area to their adult position. Another population of myogenic cells remaining in the somites segregate to a myotomal layer and eventually give rise to the back muscles.

Prior to stage 23, cells of somitic origin are dispersed throughout the limb bud; between stages 23 and 25 (3.5-4.5 days), these cells become restricted to myogenic areas of the wing and shoulder. By stage 27 ( 5 days), individual muscle primordia are distinct and myotubes become apparent. By 10 days, all brachial muscles assume their adult position.

\section{The Avian Latissimus Dorsi: I. Physiological and Structural Comparisons of the Phenotypically Affected PLD and the Spared ALD in Chickens With Hereditary Muscular Dystrophy}

Mazliah, J. and Cosmos, E. McMaster University Health Sciences Centres, Hamilton, Ontario.

Comparative histochemical and structural analyses of the anterior (ALD) and the posterior (PLD) latissimus dorsi of normal (N, White Leghorn) and dystrophic (D, Storrs birds) chickens during development ex ovo indicate that the PLD, a fast twitch glycolytic muscle with focal innervation, is a target for disease expression whereas the ALD, a slow tonic oxidative muscle with multiple innervation, is spared disease phenotypes. In addition, a comparative physiological analysis of these two synergistic muscles confirms these conclusions: Mechanical properties of the ALD muscles of both genotypes are equivalent. However, similar analyses of the PLD muscles of $N(n=40)$ and $D(n=70)$ chickens from 15 to 600 da ex ovo indicate that 1) the D-PLD demonstrates time parameters similar to those of the N-PLD, but, 2) the D-PLD cannot attain twitch or tetanic tensions equivalent to those of the N-PLD. The twitch/tetanus ratio of the D-PLD is approximately one-half that of the N-PLD. Thus, phenotypes characterizing the D-PLD are identified as an inability to differentiate metabolic enzymes associated with glycolytic muscles, structural alterations associated with destructive (and regenerative) phenomena and an inability to perform the work output of its normal counterpart. However, the DPLD demonstrates contraction and relaxation times characteristic of fast twitch muscles. Further, the enzyme associated with speed of contraction, alkali stable myosin ATPase, is shown to be histochemically similar to that of the N-PLD. On the basis of these comparative results which identify the genetically dystrophic ALD as a phenotypically normal muscle, we posed the following question: If the D-PLD could be converted to a slow tonic oxidative muscle with multiple innervation, would it also be spared $D$ phenotypes? The D-PLD cross-reinnervated (X-RI) at hatching by the ALD nerve responds by altering physiological parameters, histoenzymic profiles and structural characteristics. Of greater interest is the observation that similar X-RI experiments done with $N$ chickens indicate that the $N$ and D PLD muscles respond similarly to their respective ALD nerve, i.e., PLD fibers of $N$ and $D$ genotype successfully X-RI by their ALD nerve both yield the same phenotype.

\section{The Avian Latissimus Dorsi: II. Role of Neurons to Establish} Embryonic Enzymic Patterns

Butler, J. and Cosmos, E. McMaster University Health Sciences Centre. Department of Neurosciences, Hamilton, Ontario.

Of the two latissimi dorsi, the anterior (ALD) is a slow tonic muscle with multiple innervation whereas the posterior (PLD) is a fast twitch one with focal innervation. Histochemically, the PLD (ex ovo) demonstrates only the alkali $\left(\mathrm{OH}^{-}\right)$stable myosin ATPase reaction; however, the slow tonic ALD, unlike mammalian slow twitch fibers, demonstrates both $\mathrm{OH}$ and $\mathrm{H}^{+}$stable activity ex ovo. Following cross-reinnervation (X-RI) of the PLD muscle by the ALD nerve in newly hatched chicks of both normal and dystrophic lineage, the X-RI fibers of the PLD now demonstrate both $\mathrm{H}^{*}$ and $\mathrm{OH}^{-}$stable activity (Cosmos et al., 1979, N.Y. Acad. Sci. 317:571; Mazliah, 1979, Ph.D. Thesis). The question we posed: Does the ALD nerve serve to de-repress a repressed fetal phenotype or, instead, does it induce a new phenotype in the X-RI PLD fibers? Ontogenetic analyses using serial cryostat sections of frozen embryos from day- 2 onward reveal that myogenic cells of the wing bud, including the primordium of the ALDPLD, demonstrate a myosin ATPase reaction $\left(\mathrm{OH}^{-}\right.$stable) only after axons are demonstrated (silver-AChE reaction) to penetrate muscle masses of the wing bud (4-41/2 da). Further, as a common primordium of the ALDPLD separates into anterior and posterior portions, a simultaneous division of the common nerve sends separate nerves to the fut ure ALD and PLD. Following this event, the ALD now expresses, in addition to $\mathrm{OH}^{-}$ stable, $\mathrm{H}^{+}$stable myosin ATPase activity; the PLD never demonstrates $\mathrm{H}^{*}$ 
stable activity. This same capacity of a specific ALD nerve to induce the $\mathbf{H}+$ stable activity in fibers previously experiencing only the $\mathrm{OH}$ - stable response is noted again at hatching when the PLD muscle is coupled to an ALD nerve. Such X-RI PLD fibers for the first time in development demonstrate the $\mathrm{H}+$ stable myosin ATPase activity. Our interest in the ability of the ALD nerve to alter the phenotypic expression of the PLD is based on the observation that in the genetically dystrophic chicken (Storrs bird) the ALD muscle is spared dystrophic phenotypes. Of these two synergistic muscles, only the PLD expresses characteristics of the disease.

\section{Neural Extracts Do Not Influence Acetylcholinesterase Activity} In Muscle Cultured From Dystrophic Chick Embryos

D.D. Johnson, S. Bailey, and B. Wenger, Saskatoon, Saskatchewan

Tissue culture of skeletal muscle provides an assay system for studying the nature of mediators of neurotrophic activity and a valuable technique for investigating the role of trophic activity in normal and diseased muscle. Since chickens with hereditary muscular dystrophy have been reported to have abnormalities in acetylcholinesterase activity and muscles of this genotype may not be able to respond to neural influences, we have compared the trophic control of acetylcholinesterase (ACHE) activity in muscle cultured from dystrophic embryos to that from normal embryos. In preliminary experiments the development of ACHE activity was determined in cultures of both thigh and breast muscle from normal and dystrophic embryos. With standard culture media, no differences were noted in the development of ACHE activity in normal and dystrophic muscle. Addition of culture media containing either an extract of chick embryo brain-spinal cord or an extract prepared by ammonium sulphate precipitation of sheep sciatic nerve consistently produced a significant increase in ACHE activity in normal but not in dystrophic muscle. The data, in addition to showing that trophic activity is present in ammonium sulphate precipitated fractions of sheep sciatic nerves, demonstrate an inability of muscle of the dystrophic genotype to respond to a neurotrophic influence. Since, under standard culture conditions, skeletal muscle of the dystrophic genotype has the capability of synthesizing ACHE, the failure of dystrophic muscle to respond to a trophic influence may indicate the absence of a receptive mechanism for detecting the mediator(s) of neurotrophism.

\section{Biosynthesis of Plasma Membrane Proteins in Normal and Dystrophic Muscle \\ Paul C. Holland and G.A. Cates Saskatoon}

If the primary altered gene product responsible for muscular dystrophy is to be identified, it is necessary to study early developmental events in dystrophic muscle rather than diseased adult muscle.

We are using the muscle cell culture system to study developmental changes in plasma membrane proteins of normal and dystrophic chick skeletal muscle. This system has the advantage that any abnormalities detected can be shown conclusively to be located within the muscle cell rather than being due to neurotrophic influence. Cocultivation of nerve and muscle or addition of neurotrophic factors to the cultures are also possible in such a system if it is desired to study the neurotrophic influence as plasma membrane differentiation.

The greater synchrony of myogenesis in cell culture and its amenity to experimental manipulation also make it possible to define more precisely the stage of differentiation at which abnormalities may first be expressed.

Since little is known of the events occurring during differentiation of the normal muscle cell plasma membrane in culture we have determined the protein composition and rates of synthesis and turnover of the normal plasma membrane at various stages of myogenesis using one dimensional SDS polyacrylamide gels and two dimensional isoelectric-focussing/SDSpoly-acrylamide gel electrophoretic techniques. Changes in the orientation availability of these proteins to cell surface probes has also been examined during myogenesis and we have undertaken an immunochemical characterization of these proteins. We have compared the results obtained with normal cultures with dystrophic cell cultures in an attempt to identify abnormalities in the protein composition or orientation of proteins in the dystrophic plasma membrane. These results will be presented.

\section{The Quantitation of Free and tRNA Bound Amino Acids Obtained From Single Monolayer Cultures of Skeletal Muscle Joseph C. Bullaro, Saskatoon}

This method was developed to provide routine quantitation of individual free aminoacids and tRNA bound amino acids extracted from a single monolayer culture of skeletal muscle. Values obtained from this method will be used to: (1) correct rates of isotope uptake into protein, (2) ascertain whether in normal or dystrophic the preferred source of amino acids for protein synthesis in muscle cultures is intracellular or extracellular, and (3) ascertain whether this preference is maintained through the course of development in vitro. Cultures of 11 day embryonic chick skeletal muscle are planted with $3.5 \times 10^{7}$ cells in $100 \mathrm{~mm}$ tissue culture dishes containing $10 \mathrm{ml}$ Medium 199 supplemented with $10 \%$ horse serum, $2 \%$ embryo extract

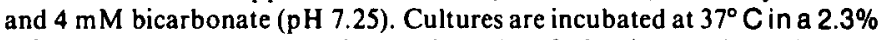
$\mathrm{CO}_{2}$ atmosphere. At 48 hrs. incubation when fusion is completed they are harvested and the cells (about $150 \mathrm{mg}$ wet weight) extracted with a phenolpotassium acetate buffer $(\mathrm{pH} 4.5)$ mixture. After a $100,000 \times \mathrm{g}$ centrifugation, the supernatant is seeded with purified yeast RNA, ethanol precipitated and centrifuged to yield a pellet containing amino acyl IRNA and a supernatant containing the free cellular pool (CP) amino acids. The $\mathrm{CP}$ fraction is evaporated to dryness in vacuo, resuspended and brought to the original aqueous volume with $0.05 \mathrm{~K} \mathrm{HCO}_{3}(\mathrm{pH} \mathrm{10)}$. The pellet (tRNAaa) is solubilized and deacylated for $1 \mathrm{hr}$. in $0.1 \mathrm{~N} \mathrm{KOH}$ and neutralized with $\mathrm{HCl}$. The deacylated tRNA sample is passed through a $0.8 \times 2 \mathrm{~cm} \mathrm{G} 25$ Sephadex column and the eluant (about $600 \mu 1$ ) lyophized and redissolved in $4 \mu 1$ of $0.05 \mathrm{~N} \mathrm{KHCO}(\mathrm{pH} 10)$. Both the tRNA and CP samples are dansylated in known specific radioactivities of ${ }^{3} \mathrm{H}$ dansyl chloride and separated by two dimensional TLC on $5 \times 5 \mathrm{~cm}$ micropolymide plates. The spots detected by UV are removed, analyzed by scintillation analysis and corrected for the \%dansylation. The pMole of each amino acid is calculated using the known specific radioactivity of the ${ }^{3} \mathrm{H}$ Dans- $\mathrm{Cl}$. The values are checked against known amino acid standards dansylated simultaneously with the unknown samples.

\section{The Changing Pattern of Protein Synthesis in the Dystrophic Chick Embryo G. Monckton and T. Nihei Alberta}

Experiments were conducted in collaboration with Dr. M. Rathbone with embryonic muscle labelled in vivo with ${ }^{3} \mathrm{H}$ leucine or ${ }^{3} \mathrm{H}$ uridine for one hour prior to dissection. One portion of individual muscle specimens was fixed and embedded in Epon for morphological study, and the other portion was frozen in liquid nitrogen. These preparations were carried out by Dr. M. Rathbone.

On tissue autoradiography, there is an abnormal uptake of ${ }^{3} \mathrm{H}$ leucine into those cells in the intermediate zone that are destined to become pectoral muscles in the dystrophic chicken.

Preliminary results suggest the uptake of ${ }^{3} \mathrm{H}$ uridine is not different between normal and dystrophic chicks at 48 hours.

Sucrose gradient centrifugation studies were carried out on the postmitochondrial fraction of muscle specimens studied morphologically. No essential difference was seen between normal and dystrophic polysomal patterns in the UV absorption patterns. Centrifugation of the polysomes through a layer of $(2.5 \mathrm{ml})$ of $2 \mathrm{M}$ sucrose in a SW 56 rotor tube eliminated much of the UV absorbing material. The gradient analyses show that the degree of recovery of monoribosomes and small polysomes to vary according to the size of the muscle specimen. No difference in polysomal pattern was detected between normal and dystrophic muscle. Measurement of ${ }^{3} \mathrm{H}$-label in the acid insoluble material sedimented along the sucrose gradient shows the amount of ${ }^{3} \mathrm{H}-$ label in the top regions of the gradient is larger in the post-mitochondrial extract of dystrophic than normal muscle. While there may be some difference in the radioactivity distributed between normal and dystrophic muscle polysomes, further studies are required to assess the significance of this observation. 


\section{Myofibril Isolation For Protein Turnover Studies in Cultured Skeletal Muscle}

R.A. Janeczko, Department of Animal Science,

University of Alberta, Edmonton, Alberta. Canada

A net negative nitrogen balance resulting in a progressive loss of protein occurs during muscular dystrophy. It is not known whether this is caused by a relative increase in the normal catabolic processes occurring during turnover in muscle or whether it is the result of processes distinct to the pathological state or a combination of both. An understanding of the mechanisms involved in normal turnover and the pathological state is therefore essential to answering these questions. Consequently we undertook an investigation of protein turnover in cultures of both normal and dystrophic muscle.

Initial studies examined the turnover of total cell protein and the effects of the protease inhibitors leupeptin and pepstatin on both synthesis and degradation in normal and dystrophic cultures. In order to study more closely the turnover of the myofibril a procedure for the isolation of purified myofibrils from cultures was developed. By maintaining striated myotubes in an extended state and by induction of rigor it was possible to obtain reasonable yields of myofibrils for analysis by SDS-polyacrylamide gel electrophoresis.

Preparations of myofibrils from cultures previously labelled with ${ }^{35} \mathrm{~S}$ methionine were used to compare turnover kinetics of myofibrils from normal and dystrophic cultures. In addition the effects of leupeptin and pepstatin on myofibrillar turnover was examined.

\section{Electrophysiological Development in Dystrophic Muscle Grown in Culture}

W.F. Dryden and C.M. Thomson, Edmonton.

Much current interest is focussed on possible lesions in membrane architecture, and we are attempting a study of the development of membrane ion conductances in cultured muscle in the belief that altered membrane structure will be manifested in virtually synchronous alterations in ion channel parameters. The contribution to overall membrane conductance made by individual ions is determined by measuring the fall in conductance either when specific antagonists are used, or when the ion in question is omitted from the bathing solution. Studies with mammalian tissue (129 REJ dy/dy mouse) are at an early stage, but data are available from normal (white leghorn) and dystrophic (Storrs) chicken. In normal chick muscle the membrane potential rises rapidly after myoblast fusion reach levels seen in adult muscle $(-70 \mathrm{mV})$. This is simultaneous with a fall in conductance from relatively high levels $(\mathrm{cal} .2 \mathrm{mScm}-2)$ to the low levels seen in developed muscle $(0.2 \mathrm{mScm}-2)$. While potassium conductance remains relatively constant during this time $(0.1 \mathrm{mScm}-2)$ chloride conductance declines $(0.7 \mathrm{mScm}-2$ to $0.2 \mathrm{mScm}-2)$ and a resting sodium conductance $(0.3 \mathrm{mScm}-2)$ disappears to be replaced by transient conductances sensitive to TTX. Dystrophic muscle membrane potential develops rapidly in culture but is not maintained and cultures degenerate after six days. Two populations of fibres seem to be present, either with normal conductances, or with very low conductances virtually devoid of a potassium component. While confirmation from further work and other strains of dystrophic chicken is required, it is possible that muscle in our system has been induced to manifest the disease.

\section{Control of Muscle Cell Growth and Amino Acid Transport}

William J. Logan, M.D., Division of Neurology

The Hospital for Sick Children, Toronto, Ontario.

Muscle cells are dependent on an adequate supply of nutrients for optimal growth and function. For amino acids and other substances there are specific transport systems in the cell membrane which serve to facilitate their transfer into the cell. The overall goals of this laboratory are to characterize these transport mechanisms to determine how they are naturally regulated (and how they can be manipulated) and to delineate their influences on muscle cell growth and metabolism. For these purposes the clonal muscle cell line in culture, the L-6 muscle cell, is a useful experimental model. In the present study, this preparation was used to investigate the response of amino acid transport systems to the experimental condition of amino acid deprivation.

Amino acid transport was determined as the initial velocity of uptake of isotopically labelled substrate by cells deprived of amino acids for five hours. Compared to the control condition, there was a greater than $100 \%$ adaptive increase in the uptake of proline and lesser increases in the uptake of several other neutral amino acids. The increase in proline uptake was not seen after 2 hours of amino acid deprivation but was distinct after $31 / 2$ hours and prominent at 5 hours. The increase could be prevented by addition of either proline or alpha-amino-isobutyric acid (AIB, a non-metabolized model amino acid which is known to utilize the same transport system as proline) to the otherwise amino acid deficient medium. Increasing concentrations of AlB were correspondingly more effective in suppressing this adaptive enhancement of uptake; near maximal suppression was seen at 1 mM AIB.

These findings demonstrate the adaptability of transport systems in muscle cells to altered growth conditions. The adaptive mechanisms may be present in intact muscle and could be impaired in certain muscle diseases.

\section{Fate of Low Molecular Weight Glycoproteins in Myoblast Cytodifferentiation}

Stephen K. Ng. Department of Biology, Erindale College, University of Toronto, Mississauga, Ontario.

It has been postulated that the plasma membrane plays an important role in the cytodifferentiation of the myoblast cells. Although changes have been observed in membrane gangliosides, it is not certain whether the membrane glyco-proteins also undergo similar changes. To investigate this aspect, tissue cultures of the rat myoblast L6 line are employed. From the parental L6 line, azacytidine resistant variants (AzaCR) has been developed. These variants are incapable of forming myotubes. The plasma membranes isolated from the fused and unfused parental lines and that of $A z a C R$ lines were compared vis SDS-PAGE analyses. Results obtained from onedimensional gel run were that, upon cytodifferentiation, two bands of the 9 and $12 \mathrm{~K}$ molecular weight bands, as revealed by Coomassie Blue stain, were absent. In the non-fusing AzaCR membrane preparations, these bands are present. Through the process of radioactive fucose, mannose, galactose, glucosamine and leucine labelling and the PAS stain, it has been established that these two low molecular weight bands are glycoproteins. It was also further established by $\mathbf{I}^{125}$ iodination process that some protein components of these two bands are present whereas the carbohydrate moieties were absent. These results were also supported by the 2 -dimensional gel runs. To investigate the possibility that fucosidase, mannosidase, galactosidase and $\mathrm{N}$-acetylglucosaminidase may be involved in the cytodifferentiation process, these enzyme activities were assayed. Results have shown that these enzyme activities were proportional to the cell growth. However, it is not clear as to whether these activities are primarily responsible to myoblast cytodifferentiation processes.

\section{Selection and Fusion Properties of Concanavalin A - Resistant Myoblast Cell Lines}

C.L.J. Parfett, J.A. Wright and J.C. Jamieson

Departments of Microbiology and Chemistry, University of Manitoba, Winnipeg, Manitoba, Canada R3T 2N2

Mammalian cell variants resistant to the cytotoxic effects of concanavalin $\mathrm{A}$ have been isolated. The concanavalin $\mathrm{A}$ resistant lines exhibit altered cell surfaces resulting in changes in some fundamental cellular properties, including: defective lectin-receptor mobility characteristics; altered lectin agglutination properties; modified adhesiveness to substratum; altered cellular morphology on solid surfaces and temperature sensitive growth characteristics. Changes in glycosyl transferase activities are probably involved in determining concanavalin $A$ resistance and the accompanying complex phenotype.

The study of concanavalin A resistance of myogenic cell lines provides an opportunity to examine the role played by the myoblast cell surface during the fusion event. Glycoproteins have been implicated in the process of normal myoblast differentiation. Results in our laboratory indicate that the concanavalin A resistant phenotype results in the loss of fusion potential in variants selected in a single step from the T984 mouse myoblast line and the 
$\mathrm{L}_{\mathrm{f}}$ rat myoblast line. The variant myoblasts are unable to undergo morphological differentiation to form multinucleated myotubes or biochemical differentiation to produce an increase in the specific activity of the muscle-specific enzyme creatine phosphokinase. These selections and experiments are currently being extended to the $L_{*}$ rat myoblast line. Further study will attempt to uncover the primary lesion resulting in altered myoblast cell surface components (presumably glyproteins) and to define their involvement during differentiation. It is relevant to note that biochemical and morphological studies suggest the presence of cell membrane abnormalities in muscular dystrophies and related disorders.

\section{A Method for the Rapid Isolation of Mitochondria From Skeletal and Cardiac Muscles Suitable for Small Tissue Samples \\ T. Goswami, R. Parvin and S.V. Pande, Montreal}

A study of metabolite level in muscle mitochondria is often hindered when mitochondria are isolated by using conventional procedures because these require considerable time and tissue amount for the preparation of mitochondria. To overcome these limitations, we have worked out a procedure that enables isolation of mitochondria not only from smaller amounts of muscle but which requires only about $1 / 4$ th as much time $(20$ min.) as conventional isolation procedures (about $90 \mathrm{~min}$.). Advantage has been taken of the fact that under suitable conditions of centrifugation, use of appropriate silicone oil layer below the homogenate allows mitochondria to pass through the oil preferentially. Using such a procedure, we are able to obtain reasonable yields (ca. $12 \mathrm{mg}$ protein per $\mathrm{g}$ rat or mouse heart and ca. $2 \mathrm{mg}$ protein per $\mathrm{g}$ skeletal muscles) of tightly coupled (respiratory control ratios of 16-25 and 16-22, respectively) mitochondria. The purity of the mitochondria thus obtained compares favourably or exceeds those obtained by others using conventional isolation procedures as judged from the specific activity of marker enzymes and ADP-stimulated rates of respiration with different substrates. The rapidity of the present isolation procedure minimizes the loss of mitochondrial substrates and cofactors and allows convenient isolation of mitochondria from small tissue samples, such as biopsy material, skeletal muscles, or heart of a mouse.

\section{A Trial of Penicillamine in the Management of the Duchenne Type Dystrophy}

E.G. Murphy, C. Vrancart, S. Jarvis, K. Fabenyi, R. Fariello and C.M. Yeung.

The Hospital for Sick Children, Toronto, Ontario. Canada.

Ten ambulant patients with Duchenne type dystrophy were treated with D-Penicillamine. The first year the dose was $25 \mathrm{mg} / \mathrm{kgm} /$ day and for the second year $50 \mathrm{mg} / \mathrm{kgm} /$ day.

The diagnosis in each patient had been fully confirmed by clinical examination, serum enzyme studies, EMG and muscle biopsy. Their ages ranged from 4-8 years.

Patients were assessed at 3 month intervals by a clinician (EGM), by a physiotherapist (CV) and by neurophysiological studies (KF). The $M$ test was performed on peripheral muscles. Serum enzyme studies relying largely on the creatine kinase evaluation was performed on each occasion.

Two brothers developed an allergic reaction to the Penicillamine and were replaced in the study by 2 other brothers. Patients were monitored carefully throughout the trial to detect renal or hematological complications associated with Penicillamine. No such complication occurred and the drug was well tolerated.

The course of the Duchenne type dystrophy is highly predictable so in a pilot trial of this type no controls were considered necessary in the original planning. After 1 year the development of contractures was not quite as much as expected clinically. Five matched controls including the 2 brothers allergic to the Penicillamine were added to the study to be followed by 3monthly assessments by the physiotherapist.

By the end of the trial it was clear that all the patients on Penicillamine had deteriorated as predictable in the usual course of the disease. This could be evaluated clinically in that 3 patients had to be braced to be kept ambulant. Objective scoring of muscle strength by the physiotherapist showed deterioration in strength particularly of the proximal muscles. Creatine kinase activity in the serum remained highly but variably elevated. The $M$ test on the peripheral muscles showed little change over the 2 year period.
The ranges of movement around the ankle were evaluated statistically and there was some suggestion that passive dorsiflexion of the ankle was not as rapid or as severe as expected and as seen in the control group.

It is concluded that D-Penicillamine alone has very little to offer in the management of the Duchenne type dystrophy.

\section{Therapeutic Trial of Oral Phenytoin in Dystrophic Chickens;}

\section{Effects Upon Contractile and Electric Properties of Muscle}

Theodore B. Hoekman, Faculty of Medicine, Memorial University

of Newfoundland, St. John's, Newfoundland, A I B 3V6, Canada.

Line 413 dystrophic, and Line 412 control New Hampshire chickens were utilized in the study. From day of hatch treated birds were presented ad lib with chick mash prepared with Phenytoin $1 \mathrm{gram} / \mathrm{kg}$. All birds in the study were subjected daily to exhaustion score testing of righting ability. When the birds reached forty-one days age, experiments began. Isometric contractile responses, and intracellular records of resting and action potentials were taken using an in vivo nerve-muscle preparation of the posterior latissimus dorsi during alpha-chloralose anesthesia. Four groups of animals were compared, normal (NU) and dystrophic untreated (DU), and normal (NP) and dystrophic treated with Phenytoin (DP). Forcefrequency relations were determined for each preparation, and concurrently rate of rise of tension-frequency relations, the twitch-tetanus ratios, post-tetanic potentiation, and post-tetanic contractures were evaluated. In comparison to Normal (N) and Dystrophic (D) birds matched for age, and not subjected to daily exhaustion score testing, there were distinct differences for all study groups in some contractile parameters. The small rates of rise of tension, and twitch-tetanus ratios, with greater posttetanic potentiation and post-tetanic contractures characteristics of D preparations, were shifted toward values seen in normal birds for both DU and DP preparations. Both NP and DP preparations showed a reduced rate of rise of tension at high frequency, and, for the latter, the post-tetanic contracture which is related to the myotonia was virtually abolished. Mean exhaustion scores were not significantly different between DU and DP birds except for a brief period at age 20-25 d.; at day of experiment both were greater than unexercised dystrophic birds. Comparison of intracellularly recorded electrical properties in untreated birds showed significant differences only with respect to the rate of rise of the action potential and its duration; all other values were equivalent (resting membrane potential, action potential amplitude and overshoot). In DP preparations there was an increase in the mean rate of rise of the action potential and a decrease in its duration, but the change was not statistically significant. Analysis of phenytoin blood levels in sa mples taken just prior to anesthesia, gave a mean value of $5.64 \pm 1.21 \mu \mathrm{g} / \mathrm{ml}$ with a range from the detection limit $(1 \mu \mathrm{g} / \mathrm{ml})$ to $15.6 \mu \mathrm{g} . \mathrm{ml}$. On an individual basis there was a strong correlation of high phenytoin levels with high exhaustion score in DP birds and a less consistent correlation with an increased rate of rise of the action potential.

\section{Microscopic Evaluation of Soleus and Extensor Digitorum Longus (EDL)} Muscles in Young Dystrophic Mice of the C57BL/6J dy ${ }^{23} / \mathrm{dy}^{2 J}$ Strain

W.K. Ovalle and S.L. Shinn, Muscular Dystrophy Research Group, Department of Anatomy, University of British Columbia, Vancouver, B.C.

Biochemical and physiological properties of the slow-twitch soleus and the fast-twitch EDL of young dystrophic (dy $2 \mathrm{~J}$ ) mice are currently being defined by others from this research group. As an adjunct to these continuing studies, corroborative morphological assessment of the two muscles was initiated in dystrophic and control animals at postnatal ages of $4,6,8,10,12$, and 20 weeks. To assess morphological change and expression of the disease at the muscle fibre and fine structural levels, techniques used included light and electron microscopy of plastic sections, and correlative histochemistry of frozen sections employing stains to assess mitochondrial/ oxidative and myosin ATPase enzyme activities.

During early phases of disease, soleus muscles generally showed more obvious and rapidly progressive pathological change than their EDL counterparts. Moreover, the histological data essentially concurred with those first reported by Butler and Cosmos that it is primarily the red, slowtwitch, oxidative extrafusal fibre type which is preferentially and initially involved. Various stages of muscle cell atrophy, myofibrillar disruption, 
and sarcotubular and mitochondrial abnormalities were noted in the affected extrafusal fibres. Endomysial connective tissue proliferation and attempts at myofibre regeneration also characterized muscles at most time periods examined. Muscle spindles, peripheral nerve trunks, neuromuscular junctions, and sensory nerve terminals appeared relatively unaffected by the disease process. Although at later stages ( 20 weeks) most extrafusal fibre types in both muscles exhibited detectable alterations in morphology and histochemistry, intrafusal fibres of muscle spindles remained virtually intact with some evidence of abnormal thickening and perineurial phagocytic activity of their capsular investment.

\section{Isometric Contractile Properties of Dystrophic Mouse Muscle of the C57BL/6J $\mathrm{dy}^{2\lrcorner} / \mathrm{dy}^{2 J}$ Strain}

Bernard H. Bressler and Johanne D. Charbonneau

Muscular Dystrophy Research Group, Department of Anatomy,

The University of British Columbia, Vancouver, B.C.

An investigation was carried out on the changes, with age, of the isometric contractile properties of EDL and SOL muscles from normal (C57BL/6J dy/dy) and dystrophic $\left(\mathrm{dy}^{22} / \mathrm{dy}^{2 J}\right)$ mice. The contractile properties of maximum isometric twitch and tetanic tension, time to peak twitch tension (TTP) and the half-relaxation time (1/2RT) were measured at 4,8 and 12 weeks of age. At 4 weeks of age there was a significant reduction in isometric twitch and tetanic tension of dystrophic SOL muscles. There was no corresponding difference seen in tetanus tension between normal and dystrophic EDL at this age. Moreover, the isometric twitch tension of dystrophic EDL was significantly increased over the control values. At 8 weeks of age a significant reduction in isometric twitch and tetanus tension for both dystrophic EDL and SOL was observed. By 12 weeks of age the dystrophic SOL continued to exhibit a decreased tension generating capacity whereas the dystrophic EDL were actually stronger than their normal counterparts. In terms of TTP and $1 / 2 R T$, at 4 weeks of age a significant increase of $1 / 2$ RT was seen only for the dystrophic SOL. At 8 and 12 weeks of age. TTP and $1 / 2$ RT were significantly prolonged in both dystrophic EDL and SOL compared to their normal counterparts. Moreover, at 12 weeks, the $1 / 2$ RT of dystrophic SOL was increased by $44 \%$ compared to $14 \%$ for the dystrophic EDL. Our findings suggest that the SOL muscle of the $\mathrm{dy}^{2 \mathrm{~J}} / \mathrm{dy}^{25}$ strain may be more severly affected in the early stages of the disease than the EDL.

\section{The Distribution of Proteins in the Slow-Twitch Soleus and Fast-Twitch} Extensor Digitorum Longus Muscles of Normal and Dystrophic Mice Laura G. Jasch. Department of Anatomy.

\section{University of British Columbia. Vancouver, B.C}

The distribution of proteins in normal and dystrophic slow-twitch soleus (SOL) and fast-twitch extensor digitorum longus (EDL) muscles was determined at $4,8,12$, and 32 weeks of postnatal development. The paired SOL or EDL muscles from one or two male C57BL/6J dy $/ \mathrm{dy}^{23}$ mice were ground in $1 \mathrm{mM}$ TRIS buffer, pH 7.4 and aliquots containing $10.4 \mathrm{mg}$ wet weight SOL or $14.6 \mathrm{mg}$ wet weight EDL were frozen in liquid nitrogen, lyophilized, rehydrated and partially solubilized in O'Farrell lysis buffer and applied to O'Farrell polyacrylamide isoelectric focusing gels. Protein groups were separated on the basis of their isoelectric points. Results indicate: 1) the normal SOL and EDL are distinguishable by their protein distributions. The SOL is characterized by two SOL-specific protein groups at $\mathrm{pI} 5.83$ and 5.47. The EDL is characterized by one EDL-specific protein group at pI 5.45 and two groups at pl 5.18 and 4.94 found in amplified levels in the EDL but at very low levels in the SOL. The EDL-specific group with pI 5.45 was isolated from the soluble portion of the muscle homogenate; all other groups were extractable with the lysis buffer from the homogenate peliet. Indirect evidence suggests the SOL-specific group with pI 5.83 is a glycoprotein. 2) The dystrophic SOL at 4 weeks is deficient in both SOLspecific groups, and by 12 weeks contains the EDL-specific group at pI 5.45. 3) The dystrophic EDL at 8 weeks contains an increased concentration of a protein group at pl 6.12 (extractable from the pellet), at 12 weeks is deficient in the EDL-specific group at pI 5.18, and by 32 weeks is deficient in the EDL-specific groups at pI 5.45 and 4.94.4) As a result of these changes and shifts in the relative amounts of other protein groups, by 32 weeks the distribution of proteins in the dystrophic SOL and EDL is identical.

\section{Motorneuronal Involvement and Fibre Type Susceptibility in $\mathbf{d y}^{2 \mathrm{j}}$ Mice \\ by D.J. Parry, Ottawa}

The question of the site of the abnormal gene expressions in murine muscular dystrophy can be asked at a number of levels. I have chosen to examine only two of these levels. 1) Is the motor-neurone involved in the disease process (and if so, at what stage of development?) 2) Are all muscle fibres equally susceptible or is there a relative sparing of certain muscle fibre types? The first question is being examined from both quantitative and qualitative viewpoints. First, is there a reduction in number of neurones in the motorneurone pool of a given muscle in $\mathrm{dy}^{21}$ mice relative to that seen in control animals. The experimental approaches being employed are both morphological (horseradish peroxidase labelling or motorneurones following intramuscular injection) and physiological (single motor unit recording in soleus muscle using conventional ventral root splitting techniques). These latter studies should also shed some light on the qualitative aspects of motorneurone involvement. It should be possible to learn whether all motor units are similarly affected or some are involved while others retain normal characteristics. The second question, that of fibre type susceptibility, has been approached by counting the proportion of the various fibre types which exhibit dystrophic morphology. This histochemical study has suggested that in the soleus muscle of $\mathrm{dy}^{2 \mathrm{j}}$ mice, at a relatively early stage of the disease ( 3 week old mice) a slightly gieater proportion of type $\mathrm{II}_{\mathrm{ox}}$ (fast-twitch?) fibres is affected than of type I (slowtwitch) fibres.

\section{Measurement of Intracellular Ionic Activity in Normal and Dystrophic Mouse Muscle Using Ion Selective Microelectrodes H. Silverman, M.P. Charlton, and H.L. Atwood Department of Zoology, University of Toronto}

Recent evidence suggests the hypothesis that the abnormal gene product associated with the $\mathrm{dy}^{2 \mathrm{~J}}$ allele in mice results in defective cell membranes. A defective cell membrane could result in an intracellular ionic imbalance. Such ionic imbalances (particularly $\mathrm{Na}^{+}, \mathrm{K}^{+}, \mathrm{Ca}^{+2}$ ) are known to cause alterations in protein metabolism in many cell types. Total elemental analysis of dystrophic mouse muscle suggest a reduction in intracellular $\mathbf{K}^{+}$ and an increase in intracellular $\mathrm{Na}^{+}$. This previous work does not take into account the mixed fiber types found in mammalian muscle, nor does it show whether the average changes are related to massive differences occurring only in highly degenerated fibers. Measurement of intracellular ions using a double-barreled microelectrode in an in vivo preparation, combined with a morphological investigation of the muscle region (the "crown" region of the gastrocnemius) studied gives a more precise estimate of the int racellular ion activity of single muscle fibers of known fiber type. Using this technique it has been possible to demonstrate a decrease in intracellular $K^{+}$in the dystrophic mouse gastrocnemius fast-twitch fibers. The decrease is not caused by a massive reduction of $\mathrm{K}^{+}$in degenerate fibers; rather, the whole population of fibers sampled in a region showing almost normal morphology had lower $\mathbf{K}^{+}$concentrations. Taken in conjunction with the elemental analysis this technique suggests that potassium binding by the intracellular organelles in normal and dystrophic fibers is similar. The ion selective electrode technique indicates that a membran abnormality causing a decrease in $\mathrm{K}^{+}$does occur in the morphologically normal fast-twitch crown fibers of the dystrophic gastrocnemius.

\section{An Immunochemical and Polyacrylamide-gel Fluorographic Analysis of the Protein Synthesized in Normal and Dystrophic Murine} Skeletal Muscle

Burr G. Atkinson and Richard R. Shivers, Cell Science Laboratories, Department of Zoology, University of Western Ontario, London, Ontario.

A number of studies, employing dystrophic skeletal muscle from different animals, indicate that the rate of protein synthesis in dystrophic muscle is considerably higher than that found in muscle from nondystrophic controls. We have also found this to be the case with muscle from the Bar Harbor ReJ 129 strain of dystrophic mouse. The general enhanced rate of protein synthesis in dystrophic muscle from this mouse is characteristic of both the sarcoplasmic and myofibrillar protein fractions. By sensitive fluorographic analysis of one- and two-dimensional 
polyacrylamide gel-separated muscle proteins and use of antibodies prepared against specific mouse muscle proteins, we have compared and assessed the diversity of the proteins synthesized and the quantity and rate of synthesis of specific myofibrillar and sarcoplasmic proteins. The dramatic decrease in the amount of CPK coupled with its apparent decreased rate of synthesis in dystrophic muscle, compared to $+1+$ control muscle, is most striking among the sarcoplasmic proteins. Although the apparent rate of synthesis for a number of myofibrillar proteins is affected in dystrophic muscle, the decreased amount and the apparent highly depressed rate of $\alpha$-actinin synthesis is extraordinary. While electron microscopic ultrastructural and freeze-fracture examinations of muscle from some of the same animals as used for these biochemical studies disclosed no lesions in the muscle membrane (the relationship of CPK quantities and lack of lesions is considered in an accompanying paper by Shivers and Atkinson), they do indicate a high deficieny in and streaming of myofibrillar Z-line structure. Since $\alpha$-actinin is a necessary and major component of the $Z$-line, we content that its depressed rate of synthesis results in myofibrillar disassembly and muscle dysfunction.

\section{Intramembrane Architecture of Dystrophic Murine Skeletal Muscle Sarcolemma; A Freeze-Fracture Study}

Richard R. Shivers and Burr G. Atkinson, Cell Science Laboratories, Department of Zoology, University of Western Ontario, London, Ontario.

Many studies have suggested that the skeletal muscle cell plasmalemma is the site where a genetically-controlled structural defect is expressed in muscular dystrophy. Ultrastructural examinations of dystrophic muscle cells have shown apparent discontinuities in the sarcolemma (termed focal lesions) which have been proposed as the sites where creatine phosphokinase (CPK) may leak out of the muscle cells. In order to more fully understand the precise nature of these hypothesized structural alterations of dystrophic skeletal muscle sarcolemmae and to try to express, in quantifiable terms, the significance of such defects as open routes to the exterior of cells, to muscle cell function and cytoplasmic CPK levels, we employed the technique of freeze-fracture to survey vast areas of intramembrane surface from dystrophic murine sarcolemmae. These intramembrane surfaces were carefully examined for evidence of perforations and/or other atypical membrane structures, and the number of intramembrane protein particles was also determined. Previous studies have successfully used freeze-fracture to demonstrate a reduction in intramembrane particles in dystrophic muscle cells and erythrocytes from dystrophic and carrier mice. None of these studies however, have reported "focal lesions" in the dystrophic sarcolemma. Results of our studies on the Bar Harbor REJ 129 strain of dystrophic mice confirm the reduced number of intramembrane protein particles reported for other dystrophic muscle sarcolemmae. More importantly, our study revealed that in no instance, was a structure observed on the intra-membrane surfaces of murine dystrophic muscle membranes that could either be interpreted as a "focal lesion" or correlated with such structures seen in thin plastic sections by other investigators. All membranes were intact and possessed only an increased number of the structural specializations commonly associated with endocytosis and/or origin of transverse tubules. Biochemical analysis of sarcoplasmic proteins from these animals showed a greatly reduced amount of CPK; a finding that suggests the enzyme may escape from the cell via an unknown route. We conclude on the basis of our findings that: 1) the "focal lesions" reported by other investigators are not a structural feature of viable dystrophic muscle cell plasma membranes and 2) although dystrophic mouse skeletal muscle cells exhibit reduced amounts of cytoplasmic CPK, which may leak from the cell, there is no morphological feature of the plasmalemma in dystrophic murine skeletal muscles that can be directly implicated in a leak mechanism. Finally, we suggest that published accounts of focal lesions in functional dystrophic muscle celis are questionable and in actual fact probably describe a structural perturbation of the plasma membrane of dead cells.

\section{Measurements of Membrane Fluidity in Dystrophic Mice}

Fumio Mizobe, Eleanora Martial and Bruce C. Livett, Montreal

Over the last few years evidence has accumulated which lends support to the idea that "a generalized membrane defect" exists in the muscular dystrophies. We are attempting to define such possible abnormalities in peripheral blood cells from dystrophic mice (C57B I and 129ReJ) using two methods, (1) temperature kinetics of a membrane-bound enzyme, AChE (Arrhenius plots), and (2) lymphocyte capping of anti-IgM receptors.

By use of density gradient centrifugation on Percoll ${ }^{\text {tw}}$, we have isolated fractions of highly purified platelets and lymphocytes from small volumes of peripheral mouse blood ( $1.5 \mathrm{ml}$ from 3 mice) with good recovery $(38 \%)$.

1. Temperature kinetics of $\mathrm{AChE}$

Since a fraction of highly purified lymphocytes obtained by the Percol! $I^{\mathrm{m}}$ technique showed virtually no AChE activity $(0.16 \pm 0.14 \mathrm{nmole} / \mathrm{min} /$ $10^{6}$ cells), we have carried out the temperature kinetics of AChE on the purified platelet fraction.

a) With mice C57B 1 strain there was no marked difference between the normal and dystrophic genotype with respect to the critical temperature $\left(T_{C}\right)$ and activation energy $(E)$.

b) For mice of the $129 \mathrm{ReJ}$ strain, there was no marked difference between normal and dystrophic with respect to the $T_{C}$ and $E_{1}$ above the $T_{C}$. There was a slight but significant difference $(P<$ $0.1)$ in the activation energy $\left(E_{2}\right)$ below the $T_{C}\left(E_{2},+1+7.85 \pm\right.$ $0.38 ; \mathrm{dy} / \mathrm{dy} 6.74 \pm 0.18 \mathrm{Kcal} / \mathrm{mole})$. This difference is, however, too subtle to allow any interpretation in terms of a change in membrane fluidity in dystrophic mice.

2. Lymphocyte capping:

For comparison with other reports in the literature the capping studies have been carried out at $37^{\circ} \mathrm{C}$. At this temperature, we found no significant difference in either the rate or extent of capping of $\operatorname{IgM}$ on purified lymphocytes obtained from normal and affected mice of either strain.

Where alterations in membrane fluidity have been observed in dystrophy they are invariably less apparent in purified and washed cell fractions, and when more specific markers were used. We believe therefore that humoral rather than intrinsic cellular influences may be responsible for the previously reported membrane abnormalities in peripheral blood cells in the murine and human muscular dystrophies.

\section{${ }^{45} \mathrm{Ca}^{2+} /{ }^{3} \mathrm{H}_{2} \mathrm{O}$ Fluxes in Peripheral Blood Lymphocytes From Duchenne Muscular Dystrophy Carriers \\ M.E. Percy*, B. Trew-Marshall**, L.S. Chang*, M.H. Freedman** and M.W. Thompson* \\ Department of Genetics, Hospital for Sick Children*,}

and Faculty of Pharmacy University of Toronto**, Toronto, Canada

Pickard et al. (N. Eng. J. Med. 299: 841, 1978) recently reported that the percentage of peripheral blood lymphocytes (PBL) which capped with fluoresceinated anti-Ig was markedly diminished in Duchenne muscular dystrophy (DMD) carriers compared to normals. We wondered if differences between DMD carrier and normal PBL could be demonstrated using a less subjective procedure, and examined ${ }^{45} \mathrm{Ca}^{2+} /{ }^{3} \mathrm{H}_{2} 0$ fluxes during the capping procedure using a method described by Freedman and Khan (Can. J. Biochem., in press) in 10 paired comparisons of cells from a normal female and a known DMD carrier.

PBL were loaded with ${ }^{45} \mathrm{Ca}^{2+}$ and ${ }^{3} \mathrm{H}_{2} 0$ at $37^{\circ} \mathrm{C}$ for $3 \mathrm{hr}$. after an overnight incubation in $\mathrm{Ca}^{2+}$-free medium. At this stage of the procedure, the ratio of ${ }^{45} \mathrm{Ca}^{2+} /{ }^{3} \mathrm{H}_{2} \mathrm{O}\left(\mathrm{R}_{1}\right)$ was lower in the carrier preparation than in the normal in $7 / 10$ experiments.

The cells were then incubated in the presence of isotopes at $4^{\circ} \mathrm{C}$ with antiIg antiserum for $1 \mathrm{hr}$. and then transferred to $37^{\circ} \mathrm{C}$ to initiate capping. After $20 \mathrm{~min}$. at $37^{\circ} \mathrm{C}$, the ratio of ${ }^{45} \mathrm{Ca}^{2+} /{ }^{3} \mathrm{H}_{2} \mathrm{O}\left(\mathrm{R}_{2}\right)$ was lower in the carrier preparation than in the normal in 8/10 experiments.

Since $R_{1}$ and $R_{2}$ both tended to be lower in DMD carriers than in normals, we added these parameters to accentuate the differences. $R_{1}+R_{2}$ values were significantly lower than normal in DMD carriers $(P<.05)$ using both a Student's t test for paired comparisons and a Wilcoxon matchedpairs signed rank test.

This study suggests that the gene defect in DMD is expressed in, or affects, peripheral blood lymphocytes. We are exploring the possibility that ${ }^{45} \mathrm{Ca}^{2+} /{ }^{3} \mathrm{H}_{2} 0$ flux measurements can be used in DMD carrier diagnosis.

\section{Myelination in the Peripheral Nerve of Normal and Muscular Dystrophic Chicks During Development \\ C. Mezei, Halifax, N.S., Canada.}

The primary molecular abnormality for muscular dystrophies has not 
been determined yet. One of the hypotheses for the pathogenesis of these diseases is that it may be caused by an abnormal influence of nerve on muscle. The inherited muscular dystrophy of the chicken has a number of features similar to those of human Duchenne muscular dystrophy. It therefore provides an animal model to test the hypothesis that the primary defect in this disease is the abnormal biogenesis or assembly of the myelin sheath in the peripheral nerve. The abnormality in turn may be due to a defect either in the trophic influence of the neurons of axons to be myelinated or in the myelinating Schwann cells or both.

The overall objective of this project therefore is to compare the biogenesis and assembly of the myelin membrane in the peripheral nervous system (PNS) of normal and muscular dystrophic chickens. To study this process we need specific myelin markers. One of the best markers is the $30 \mathrm{KD}$ or PO protein which constitutes more than $50 \%$ of the PNS myelin proteins. We started to purify PO protein from compact myelin of the sciatic nerve of 7-day chicks. The purification procedure involved 2 cycles of SDSSepharose B6-CL column chromatography and preparative polyacrylamidegel electrophoresis.

The pure PO protein will be used as an antigen to develop a radioimmunoassay. This assay will help us to elucidate the temporal and chemical events leading to the formation of compact myelin in the dystrophic and normal animals during development.

\section{Highly Localized Alterations in Endogenous Phosphorylation of Myelin Proteins in Murine Dystrophy \\ By Elena H. Petrali and Prakash V. Sulakhe \\ Department of Physiology, College of Medicine, University of Saskatchewan, Saskatoon.}

Several morphological studies have shown that in the dystrophic mouse (129 ReJ, dy/dy) the nerves that supply the hind limbs display abnormalities in their myelination at the dorsal and ventral roots and that these reportedly occur at a very early age. Recently, we have shown that endogenous protein kinase-catalyzed phosphorylation of myelin-specific proteins is markedly stimulated by $\mu \mathrm{M} \mathrm{Ca}^{2+}$, but not by cyclic nucleotides (Petrali and Sulakhe, Can. J. Physiol. Pharmacol; Enzyme, in press; Petrali et al., Int. J. Biochem., in press; Sulakhe et al., Biochem. J., in press). In view of the peripheral nervous system (PNS) myelin deficits of the dystrophic mice, we investigated the calcium stimulated phosphorylation of myelin proteins in myelin isolated from various regions of the PNS and CNS of normal and genetically dystrophic mice. In the case of normal mouse CNS myelin, small (SBP) and large (LBP) basic proteins were phosphorylated whereas in the case of PNS myelin, a glycoprotein $\left(\mathrm{P}_{0}\right)$ and basic proteins $\left(P_{1}\right.$ and $\left.P_{2}\right)$ were phosphorylated. $\mathrm{Ca}^{2+}$, but not cyclic AMP, markedly (5 to 10-fold) stimulated phosphorylation of the PNS and CNS myelin proteins. A marked decrease in the cauda equina (PNS) myelin phosphorylation of the dystrophic mouse was observed whereas the dystrophic sciatic nerve myelin phosphorylation, compared to normal, was higher. There was no difference between the normal and dystrophic mouse CND myelin phosphorylation. The details of these findings and their likely significance will be presented.

\section{Evidence For Undifferentiated Schwann Cells In} The Spinal Roots Of Dystrophic Mice

\section{Suzanne Perkins, Garth M. Bray and Albert J. Aguayo} Montreal

The spinal roots of dystrophic (dy) mice contain bundles of unensheathed axons and a few myelinated fibers. The myelinated fibers are associated with normal-appearing Schwann cells while the bundles of naked axons often appose poorly-differentiated cells not seen elsewhere in the PNS. Unlike normal Schwann cells, these "uncommitted" cells continue to multiply in the adult mice.

In an effort to determine if a genetic abnormality of Schwann cells is responsible for the dy root abnormality, L3 or L4 spinal roots from C57BL/ $6 \mathrm{~J} \mathrm{dy} / \mathrm{dy}^{25}$ mice were grafted into the sciatic nerves of host mice. To permit identification of donor and host Schwann cells, Trembler mice mutants with a primary Schwann cell abnormality which causes severe PNS hypomyelination were used as hosts. Donors were adult dy mice in which uncommitted cells had been labelled by daily injection of ${ }^{3} \mathrm{H}-\mathrm{T}(4 \mu \mathrm{Ci} / \mathrm{g}$ body weight) for the 20 days prior to grafting. Autoradiography of 4 ungrafted roots from 2 labelled mice showed that many uncommitted cells, but not the typical Schwann cells, were labelled.
Six or eight weeks after grafting, host mice were sacrificed and the grafted nerves embedded in epoxy resin. By phase microscopy, the graft segments resembled normal regenerated nerve, while outside the graft the sciatic nerve retained the appearance of a Trembler nerve. Electron microscope autoradiography of the transplanted roots showed that, in the 77 labelled cells identified, $48 \%$ were typical remyelinated Schwann cells, $47 \%$ were cells resembling the uncommitted cells of dy roots and the rest were other cell types.

These results suggest that the uncommitted cells of the dy mouse spinal roots may be Schwann cells at an arrested stage of differentiation. Because these cells are able to ensheath axons when transplanted to a foreign nerve, the abnormality of the dy mouse spinal roots is likely due to factors extrinsic to the Schwann cell.

\section{Gene Product Distributioin In Mosaic Skeletal Muscle Fibres Frair, P.M. and Peterson, A.C. Montreal, Quebec}

During the primary development of vertebrates, mononucleated myoblasts undergo fusion of their cytoplasm to form multinucleated myotubes. The individual nuclei remain distinct, and in mature mammalian myofibres they are located at regular intervals along the length of the cell. We have been interested in the spatial extent of the influence of individual nuclei in the myofibre syncitium. In particular, we have asked; are the gene products of each nucleus distributed throughout the cell or do products remain within local cytoplasmic territories around the nucleus that directed their synthesis?

To address the question. we have analyzed the distribution of gene products along the length of muscle cells that contain two genotypically distinct types of myonuclei. These mosaic muscle cells were obtained from mouse chimaeras that had been produced by the aggregation of embryos that differed in the electrophoretic variants of the cytoplasmic enzyme, glucosephosphate isomerase (GPI-1., E.C.5.3.1.9.). The quantitative electrophoretic analysis of GPI-1 variants in mosaic muscle cells revealed that there was no change in the isozyme composition over distances up to 1 $\mathrm{mm}$ of fibre length. Thus there was no evidence that GPI-I was localized in cytoplasmic territories.

The enzymatically active form of GPI-1 is a dimer formed by the aggregation of monomer gene products. The proportions of heterodimers in the chimaera muscle fibres indicated that it is the enzyme monomers or their precursors that are widely distributed. These and other studies are consistent with the hypothesis that multiple nuclei co-operate in the maintenance of each region of the cytoplasm of skeletal muscle fibres.

Muscle fibres in carriers of the X-linked Duchenne Muscular Dystrophy are expected to contain nuclei in which both the normal $X$-chromosome is active and nuclei in which the active $X$-chromosome bears the abnormal gene. If the site of expression of the DMD gene is the myonucleus, then, on the basis of our studies of mouse chimaeras, we would predict that there is a homogeneous mixture of the normal and abnormal gene products in the mosaic muscle fibres of carriers of DMD.

\section{Dystrophic - Normal Mouse Chimaeras: Extramuscular Influences In the Expression of the Muscle Disease \\ Alan C. Peterson, Pat Frair, Helen Rayburn and David Cross McGill University, Montreal}

All somatic cells comprising an individual are expected to contain an identical set of genes and therefore, all differentiation is thought to reflect differential expression of that common genetic library. In patients and animals with hereditary muscular dystrophy the nuclei of all somatic cells contain the fundamental genetic abnormality. However, we know nothing whatsoever regarding the identity of cells that either attempt to express the critical gene product or have an absolute requirement for it. Consequently. the muscle diseases that we study could equally result from either an intrinsic deficiency in the muscles, realized when myonuclei are required to express the dystrophic gene locus, or, from one or more abnormal influences imposed upon the muscle by some other tissue in which expression of the dystrophic gene locus occurs. For the mouse, this issue has been the focus of exhaustive experimentation but as yet no compelling evidence 'for either mechanism has emerged.

To approach this problem we have used the mouse chimaera preparation. Chimaeras are individual mice that have developed from not one, but from 
two genotypically distinct populations of cells. These genetic composites provide unique opportunities to investigate whether the genetic composition of any particular tissue coincides with its phenotype. If genotype and phenotype always correlate, an intrinsically expressed defect is likely, and if they do not, extrinsic influences are indicated. Chimaeras of muscular dystrophic - normal constitution have been observed to contain muscles of dystrophic genotype that nonetheless reveal a substantially normal phenotype. An extramuscular influence is therefore revealed. Of particular interest, we have also observed chimaera muscles that express typical pathology and one of these has a significant population of genotypically normal myonuclei. These results suggest that expression of the dystrophic gene in an as yet unidentified non-muscle cell type results in an internal environment not compatible with normal muscle development and maintenance. These experiments and further potential applications of the chimaera preparation will be discussed

Abnormal Age-Associated Immunoregulation in Muscular Dystrophic Mice

Myron R. Szewczuk, McMaster University Medical Centre, Hamilton, Ontario.

The age-associated changes in B-cell function in normal and dystrophic mice were studied. Various aged normal $(+/+)$ and dystrophic $\left(\mathrm{dy}^{2 /} / \mathrm{dy}^{2 j}\right)$ C57B1/6J strain mice were immunized with trinitrophenylated bovine gammaglobulin (TNP-BGG) in complete Freund's adjuvant, intraperitoneally. The number of splenic anti-TNP antibody-forming cells (PFC) and the distribution of avidity of PFC was assayed two weeks later. One month old dystrophic mice produced a significant decrease in the number of $1 \mathrm{gM}$ and IgG PFC's and a markedly restricted heterogeneity of affinity of IgG PFC's as compared to normal mice. Two month old dystrophic mice produced enhanced PFC's and more highly heterogeneous IgG PFC's with respect to antibody affinity, as compared to normals. The number of splenic nucleated cells in the normal and dystrophic mice were found not to be different. The results imply an abnormal change in the regulation of the immune response which occurs in dystrophic mice between $I$ and 2 months of age.

Studies on Thymic Influences in Genetic Muscular Dystrophy in Mice C.E. Slonecker, W.K. Ovalle, B.H. Bressler, L.G. Jasch,

Department of Anatomy. The University of British Columbia, Vancouver, B.C.

Studies by de Kretser and Levitt reported that marked alterations in thymic structure were evident in all Bar Harbour 129/ReJ strain mice which expressed gross signs of muscular dystrophy. The structural alterations which they noted were a marked decrease in the lymphoid cell population and a hyperplasia of the epithelial components within the thymus gland. These changes suggested that impaired immunological mechanisms and/or the secretion of a thymic trophic factor may be related to the expression of Muscular Dystrophy in these genetically dystrophic mice. Karmali and Horrobin independently confirmed these observations of marked thymic changes in dystrophic mice. The hypothesized "that muscle and thymus are damaged by the basic genetic defect but that the clinical expression of the genetic defect in the muscles may depend on some of the consequences of thymus damage".

Our studies are assessing the influences that neonatal thymectomy has on the expression of microscopic, physiological and biochemical changes in the fast and slow muscles in C57BL/6J dy $/ \mathrm{dy}^{2 \mathrm{~J}} \mathrm{dystrophic} \mathrm{mice.} \mathrm{We} \mathrm{are}$ also assessing the changes in these parameters when subsequent thymic transplantations from normal and dystrophic mice are placed subcutaneously in neonatally thymectomized dystrophic and normal recipients, respectively. The alterations in histochemical profiles, ultrastructure, contractility and distribution of proteins are believed to be a more sensitive criterion for assessing the possible immunological or hormonal influences that the thymus may be working in the expression of Muscular Dystrophy in these mice.

\section{Thymic Mast Cells in the Genesis of Avian Muscular Dystrophy}

A. Dean Befus, Neil Johnston, John Bienenstock, Jane Butler and Ethel Cosmos.

Hamilton.

Mast cells are widely recognized for their role in allergic reactions, but their near ubiquitous distribution in the body and proliferation in various pathological conditions implies that they also function in other ways. Recent developments have shown that histamine, a prominent mast cell component, can stimulate the differentiation and regulate the functions of certain cells. Mast cell increases have been identified in the skin and muscle of dystrophic mice and in patients with dystrophia myotonica there is an elevation in urinary histamine levels.

In dystrophic animals the thymus develops abnormally and the ability to reject allografts of skin and muscle, a thymus-dependent response, is depressed. There is evidence that these thymic defects may be important in the genesis of dystrophic muscle. In normal animals, the thymus is a rich source of mast cells and histamine, but the role of the mast cell in in vivo thymic function is unknown, although histamine will induce the differentiation of thymocytes in vitro. Thus, as dystrophic animals have both thymic abnormalities and mast cell changes in other tissues, we investigated the distribution and abundance of mast cells and histamine in the thymus of normal and dystrophic chickens. Our results show that the thymus of adult dystrophic birds has a deficiency in mast cell numbers and histamine content. This deficiency may be of fundamental significance in the abnormal thymic-muscle interaction postulated in the dystrophic process.

Investigations of Possible Immunocyte Involvement in the Murine Muscular Dystrophies

Susan Colby-Germinario, Eleanora Martial and Bruce G. Livett, Montreal

Evidence has accumulated suggesting that "a generalized membrane defect" may be involved in the etiology of the various human and animal muscular dystrophies. Membrane integrity is essential for functional cellcell interactions, for example, the immune response. Two studies have shown significant depletion of lymphoid cells in spleen and thymus of dystrophic mice. In addition, there are conflicting reports concerning the ability of immunocytes from thymus, spleen and peripheral blood of normal and dystrophic sources to cap membrane-bound receptors. In an initial at tempt to assess whether cellular immune function is altered in these disorders we have measured hematological and immunological parameters in normal and dystrophic mice of the $129 \mathrm{ReJ}$ and C57BI strains.

Blood collected by the retro-orbital approach has been subjected to routine hematology and differential cell counts. In addition we compared the ability of normal and dystrophic animals to reject skin allografts and autografts to assess the competency of the cellular immune response. Because there is evidence for an altered time course of development of the thymus and spleen in dystrophic mice we also examined the time of onset of graft rejection.

The results of our preliminary studies suggest an immune deficiency in dystrophic mice of both $\mathrm{C} 57 \mathrm{BI}$ and $129 \mathrm{ReJ}$ strains within the first six weeks of birth. The ability of these animals to reject a skin graft is impaired (increased graft injection time) at a time when previous studies have shown marked alteration in thymic morphology and decreased weight of the thymus. Further, the difference in graft rejection times is more significant the earlier the age of the animal. These allograft rejection studies need to be extended to a larger population, and at earlier ages ( 2 - 3 weeks), and the effect quantitated and confirmed by other in-vitro tests of cellular immunity.

If there is "a generalized membrane defect" we would expect that membrane-related functions of cells of the immune system would be affected. These studies should therefore help to elucidate whether such changes affect the development and/or function of the cellular immune system in murine muscular dystrophy.

\section{Genetically Dystrophic Chicken Employed as} Model for Drug Therapy Screening

M.S. Hudecki, C.M. Pollina, A.K. Bhargava, R.S. Hudecki, and R.R. Heffner

Department of Biological Sciences, Department of Pathology,

State University of New York at Buffalo; Roswell Park Memorial Institute, Buffalo, N.Y.; Department of Biology. 
Erie Community College, Buffalo, N.Y.

There is no effective form of chemotherapy available to humans affected with the major types of hereditary muscular dystrophy. This dilemna has led us to test various agents with diverse pharmacologic action on Line 413 dystrophic chickens. This myopathy is characterized by (1) a progressive loss in functional ability, (2) abnormal plasma enzyme activity, and (3) marked muscle degeneration.

To evaluate the effects of IP drug treatment all experimental chickens were (1) subjected to a standardized, periodic functional test for righting ability. (2) bled weekly for plasma enzyme and metabolite levels, and (3) the affected p. major muscle histology routinely analyzed.

Significant yet temporary improvement in functional ability has in many cases been demonstrated in dystrophic chickens treated with various antiserotoninergic drugs, alone or in combination with penicillamine. Alternate regimens of steroidal and non-steroidal anti-inflammatants, calcium antagonists, proteinase inhibitors, or branched-chain amino acids have in many cases prolonged functional ability. Reductions in plasma enzymes (e.g.. creatine phosphokinase) and blood serotonin are often associated with therapy. No significant association has yet been observed between the various drug regimens and an improved muscle histology.

Possible amelioration of the human dystrophies through drug intervention are thought to exist in the intensive study of animals with a genetic myopathy.

Regulation of Protein Synthesis in Embryonic Chicken Muscle by Proteins that Bind to Messenger Ribonucleic Acids By Jnanankur Bag and Bruce $\mathrm{H}$. Sells

From the Molecular Biology Laboratories, Faculty of Medicine, Memorial University, St. John's Newfoundland, Canada.

In the cytoplasm of embryonic chicken muscle a considerable portion of messenger RNAs exists outside the polysomes as ribonucleoportein complexes (free mRNP). These free mRNP complexes have been implicated in the regulation of protein synthesis during myogenesis. To determine the mechanism by which these free $m R N P$ complexes may exert their regulatory effect, we have undertaken an investigation of the protein components of these complexes.

The protein moieties of the purified free mRNP complexes of embryonic chick muscle have been analyzed for the presence of regulatory molecules. A cyclic-AMP independent protein kinase activity was found associated with the free mRNP. This enzyme catalyzes the transfer of phosphate group(s) from ATP to at least three acidic free $m R N P$ polypeptides of $\mathrm{Mr}=$ $27,000,38,000$ and 73,000 and one basic polypeptide of $\mathrm{Mr}=75,000$. Among these the $\mathrm{Mr}=38.000$ polypeptide was the best acceptor of phosphate groups. In contrast, ribosomal proteins were found to be poor acceptors. The characterization of the protein kinase and its role in regulation or protein synthesis is currently being studied in this laboratory.

In addition to the free $\mathrm{mRNP}$ complexes in the cytoplasm of muscle cells we have observed the presence of a soluble pool of R NA-binding proteins. These proteins have components which showed electrophoretic migration properties similar to those of RNP polypeptide of free $\mathrm{mRNP}$ complexes in bidimensional gel electrophoresis. Furthermore, a cyclic-AMP independent protein kinase activity was also present in these RNA-binding proteins. The RNA-binding proteins contained endogeneous substrates of which a $\mathrm{Mr}=38,000$ polypeptide was the strongest acceptor of phosphate groups. These proteins displayed a preference for binding to mRNAs and were able to inhibit the translation of mRNAs in a cell-free system.
The role of these proteins in the regulation of muscle protein synthesis under normal and pathological conditions is currently being investigated.

\section{The Effect of Phenytoin on Membrane Protein Phosphorylation in Patients With Myotonic Muscular Dystrophy \\ Vickers, J.D., Fraenkel, D., McComaś, A.J. and Rathbone, M.P.} Hamilton, Ontario.

Phenytoin (diphenylhydantoin) has been shown by Roses and coworkers to reduce the membrane lipid fluidity of erythrocyte of patients with myotonic muscular dystrophy (MyD).

The effect of phenytoin on erythrocyte spectrin and band 3 protein phosphorylation, which is reduced in MyD patients, was investigated.

In one series of experiments phenytoin was included in the phosphorylation assay mixture with normal or MyD erythrocyte membranes (ghosts). Phenytoin caused an apparently non-specific reduction in phosphorylation of band 3 protein and to a lesser extent spectrin in both normal and MyD ghosts.

In the second series of experiments, normal and $\mathrm{MyD}$ erythrocytes were incubated with $1 \times 10^{-5}, 1 \times 10^{-4}$ and $5 \times 10^{-4}$ the phenytoin for 16 hours at $37^{\circ} \mathrm{C}$. The incorporation of $\left[{ }^{32} \mathrm{P}\right]$ phosphate from $\left[\gamma^{32} \mathrm{P}\right] \mathrm{ATP}$ into ghosts prepared from these erythrocytes was determined. Phenytoin, in the preincubation with intact MyD erythrocytes, increased the phosphorylation of spectrin in the subsequently prepared ghosts but had no effect on phosphorylation of ghosts from normal erythrocytes.

It is suggested that phenytoin, added to intact MyD erythrocytes, may indirectly reduce the level of spectrin phosphorylation, in situ. This would make more sites available for subsequent incorporation of $\left[{ }^{32} \mathrm{P}\right]$ phosphate into ghosts.

These results demonstrate that a second alteration of the MyD erythrocyte membrane is affected by phenytoin indicating that altered protein phosphorylation and lipid fluidity are related and that an understanding of this effect of phenytoin may clarify the nature of the MyD erythrocyte membrane abnormality.

\section{Parallels Between Zinc Deficiency, Essential Fatty Acid Deficiency and Myotonic Dystrophy \\ D.F. Horrobin, Montreal H3E 1J8}

Zinc deficiency, essential fatty acid (EFA) deficiency and myotonic dystrophy have a number of features in common. They include hair loss, testicular atrophy, cataract formation, abnormalities of lipid metabolism and insulin resistance. Zinc seems to be necessary for the conversion of EFAs to PGEl and in zinc-deficient rats we have shown that most of the features of zinc deficiency can be reversed by increasing PGEI formation by other means. PGEl may also be involved in muscle regulation since PGEI infusions cause profound weakness and agents which enhance PGEI formation can cause a myasthenia-like syndrome. It is therefore possible a lack of PGEI could be involved in myotonia.

These observations raise the possibility that deficient formation of PGEI may be involved in myotonic dystrophy. There are a number of nutritional and pharmacology techniques whereby PGE! synthesis can be enhanced and we are interested in cooperating with clinicians in the organisation of a clinical trial. 